\title{
Inclusion Modeling of Bucket Elevator Conveyor Chain Links
}

\author{
Edward Yin $\mathbb{D}^{1},{ }^{1}$ Onesmus Muvengei, ${ }^{2}$ and John M. Kihiu ${ }^{2}$ \\ ${ }^{1}$ Department of Mechanical Engineering, University of Mines and Technology, Tarkwa, Ghana \\ ${ }^{2}$ Department of Mechanical Engineering, Jomo Kenyatta University of Agriculture and Technology, Juja, Kenya \\ Correspondence should be addressed to Edward Yin; eyin@umat.edu.gh
}

Received 21 May 2020; Accepted 24 July 2020; Published 4 September 2020

Academic Editor: Yuanxin Zhou

Copyright (c) 2020 Edward Yin et al. This is an open access article distributed under the Creative Commons Attribution License, which permits unrestricted use, distribution, and reproduction in any medium, provided the original work is properly cited.

Inclusions, pores, and cracks which are defects in materials are important in determining the structural integrity and durability of components. Modeling accurately, these defects are hence of interest to both theorist and the practitioner. CAD models were designed using Autodesk Inventor software, and simulation was performed using ANSYS academic software. Material saving in design of conveyor chain links has gained popularity, and this has led to the introduction of necks in its geometry. However, the effect of necking on various parameters was not considered. Also, inclusions which are defects in material are known to have adverse effect on the conveyor chain link. It is, therefore, imperative to predict numerically, the effects that inclusions and necking have on conveyor chain links This paper focusses on modeling nonmetallic inclusions and also tests various models of different neck radii using the finite element method so as to predict its effect.

\section{Introduction}

Defects such as pores, cracks, and inclusions are important to the structural integrity and durability of components. The accurate model of voids and inclusions is hence of interest to both theorist and the practitioner. The failure process of most metals and alloys is strongly connected to the material microstructure, especially with the microstructural defects.

The evolution behavior of defects in steels during rolling severely affects the rolled products quality. Discontinuities in castings, such as inclusions and porosity, play an important role in casting underutilization. These discontinuities create uncertainty in a design's robustness, since there are no methodologies for including its presence in the design. As a result, designers employ overly large safety factors to entire parts to ensure reliability.

Inclusions play a vital role in fatigue failure of materials and the initiation of this mechanism and early growth involves cracking of the inclusion itself, debonding of the inclusion/matrix interface. For many metals, fracture strength and fatigue lifetime are controlled by small defects that grow at various sizes.

Conveyor system is a mechanical system used in moving materials from one place to another and finds application in most processing and manufacturing industries such as chemical, mechanical, automotive, mineral, and pharmaceutical electronics. It is an easier, safer, faster, durable, reliable, more efficient, and cheaper means of transporting materials from one processing stage to another compared to manual handling. Material handling is an important factor in manufacturing, and therefore, the efficiency of material handling equipment adds to the performance level of a firm [1].

Chains are made up of a number of rigid links which are hinged together by pin joints in order to provide the necessary flexibility for wrapping around the driving and the driven sprocket. These sprockets have projection teeth of special profile and fit into the corresponding recess in the link of the chain. Chain strips are machine elements that are subjected to extreme service conditions, such as high tensile loads, friction, and sometimes aggressive operating environment which includes presence of humidity, seawater, and chemicals, among others.

Apart from tensile overload fracture, double shear is also a common failure mechanism which occurs under lower applied loads [2]. As these chains operate under various forces, failure of chain assembly is the major problem. The causes of these failures may include improper material 


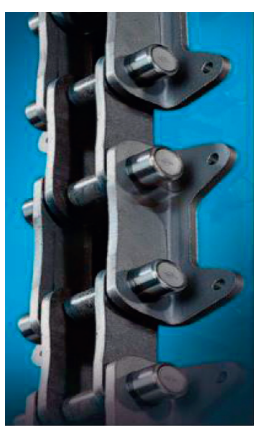

(a)

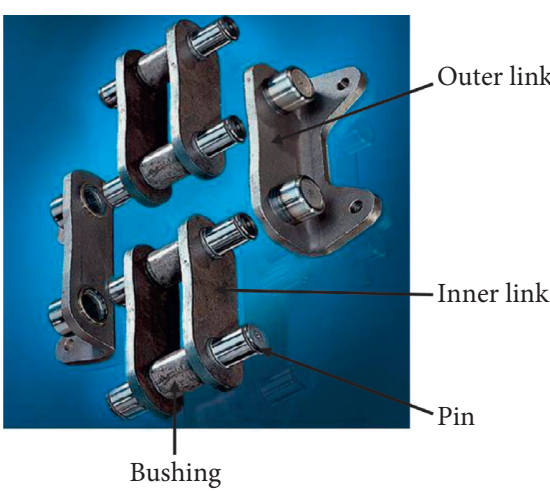

(b)

FIgURE 1: Typical chain link assembly.

selection, uncertainties in manufacturing, and faulty manufacturing processes. The chain link is made up of an inner and an outer link which are press fitted to form a continuous chain.

Figure 1 shows the various components of the conveyor chain link that are assembled to form a continuous chain.

Inclusions are produced when the quantity of metal added is greater than necessary to kill steel. The remaining metal combines with oxygen to form inclusions. Yin et al. [3] in their research determined experimentally the root cause of failure of conveyor chain links. The researchers concluded that inclusions were the root cause of failure of conveyor chain links. The metal usually used in killing steels is aluminum $[4,5]$. Since inclusions cannot be eliminated completely from steels, it is imperative to modify them with calcium in terms of chemical composition to minimize their harmful effect [6]. One of the essential tasks in the steelmaking process is to control nonmetallic inclusions, their amount, composition, size, and other properties. The composition of the inclusions can be controlled through the chemistries of the metal and the slag. Deoxidation is an important start for a kind of inclusion path. The practice of adding calcium to steels for the reduction and control of sulphide and oxide inclusions is now used worldwide [7].

\section{Literature Review}

The various literature studies pertaining to this work are reviewed. Jagtap et al. [2] studied analytically, experimentally, and numerically the behavior of a roller conveyor chain strip under tensile loading. Comparison was made between the three methods, and the results showed that they are within $+/-10$ percent of the calculated working stress. It was deduced that the fatigue cracks initially nucleated at the external cracks of the link, and later propagated to the inside of the links until sudden fracture occurred. It was concluded that a roller chain drive may be subjected to tensile loads; thus, it must have high tensile strength to withstand the wide range of tensile loads that may be imposed on it. In this paper, comparison between the results obtained from experimental, analytical, and numerical showed a deviation for which the reasons behind the deviation were not stated.
Kulkarni and Patil [8] carried out failure analysis and weight optimization on conveyor chain numerically using ANSYS simulation software. The aim of the study was to reduce the weight of conveyor chain link through material changes by proposing E-glass epoxy and carbon epoxy material. For E-glass epoxy, as the thickness was increased from $5 \mathrm{~mm}$ to $15 \mathrm{~mm}$, the equivalent stress generated varied from $386.01 \mathrm{MPa}$ to $128.3 \mathrm{MPa}$ which were below the ultimate tensile strength $(1500 \mathrm{MPa})$ of the material considered [9]. The deformation was found to be decreasing steadily from $0.23217 \mathrm{~mm}$ to $0.073205 \mathrm{~mm}$. For carbon epoxy, as the thickness was increased from $5 \mathrm{~mm}$ to $15 \mathrm{~mm}$, the equivalent stress generated in the link varied from $786.26 \mathrm{MPa}$ to 250.08 $\mathrm{MPa}$ which were also below the ultimate tensile strength $(1600 \mathrm{MPa})$ of the material considered, whereas deformation was found to be decreasing steadily from $0.11295 \mathrm{~mm}$ to $0.036593 \mathrm{~mm}$. The weight obtained from $15 \mathrm{~mm}$ equivalent thickness of steel, E-glass epoxy, and carbon epoxy was $98 \mathrm{~kg}, 75.11 \mathrm{~kg}$, and $59.78 \mathrm{~kg}$, respectively. A $23.71 \%$ weight reduction was obtained for E-glass epoxy, whereas for carbon epoxy, 39\% weight reduction was achieved. Hence, it was concluded that E-glass epoxy was the best alternative to the steel link as it was safe, generated lower stress levels and at the same time resulted in $23.71 \%$ weight saving.

Barge and Gaikwad [10] employed finite element analysis (FEA) to conduct shape and weight optimization of roller chain outer link plate by changing the shape of outer link plate. The work was validated by carrying out experiments on the optimized outer link of the conveyor chain link. The authors used shape finder plot, von Mises stress plot, and displacement plot to obtain an optimized shape for the outer chain link. The failure of the outer link was predicted to occur around the hole as there was a maximum stress concentration around the hole. The maximum stress obtained at a maximum load of $269.3 \mathrm{kN}$ was $820 \mathrm{~N} / \mathrm{mm}^{2}$. A maximum displacement of $0.1226 \mathrm{~mm}$ was also obtained around the hole emphasizing the fact that failure was likely to occur around the hole. Experimental results showed that the maximum stress was 821.87 occurring at a maximum load of $282.96 \mathrm{kN}$. The failure occurred around the hole as predicted by the numerical results. Based on the FEA and 


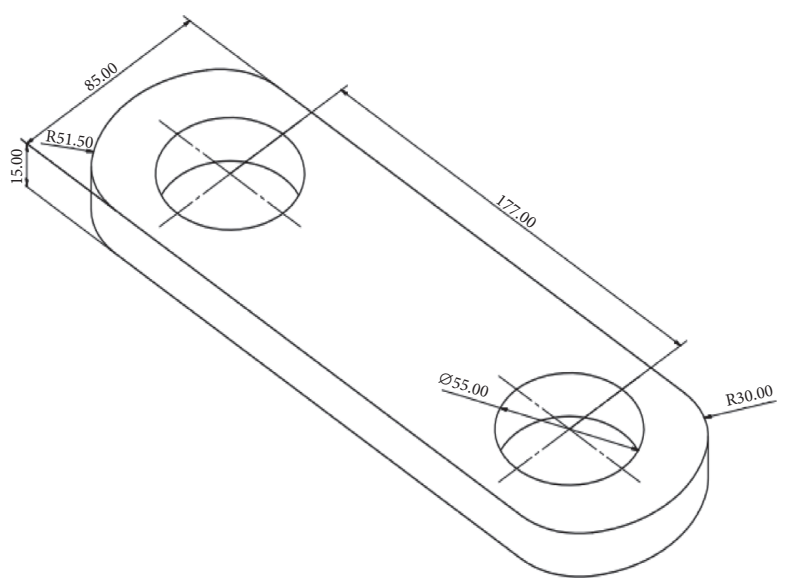

(a)

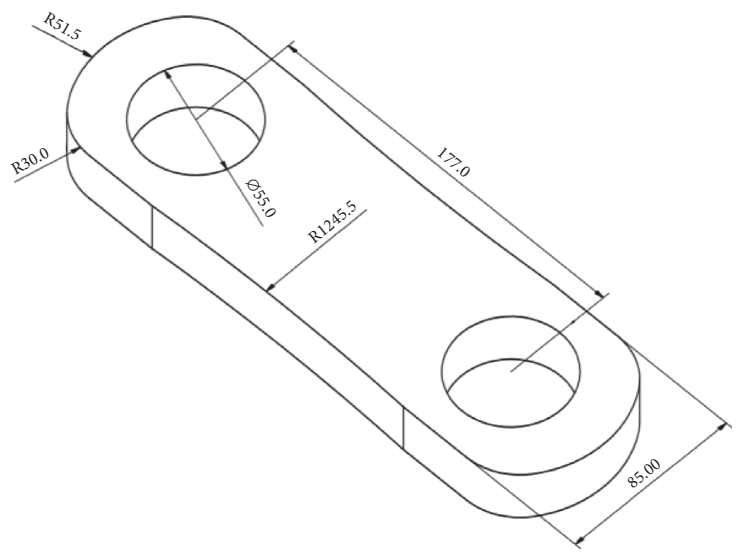

(c)

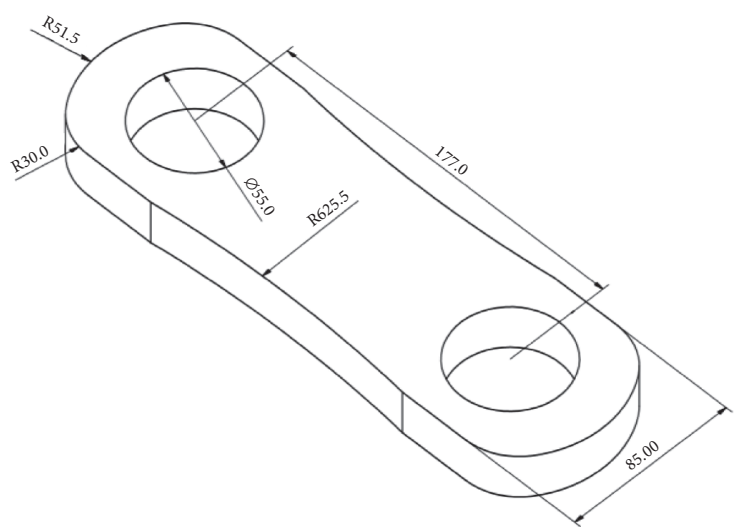

(e)

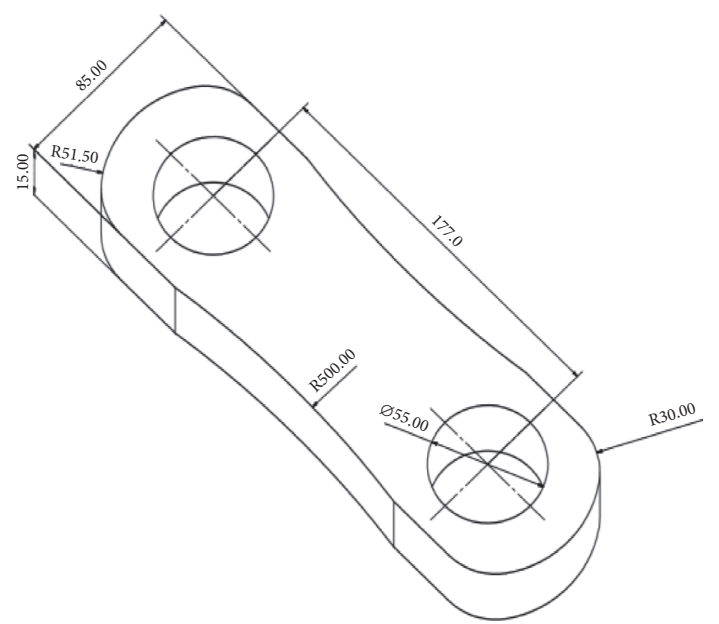

(b)

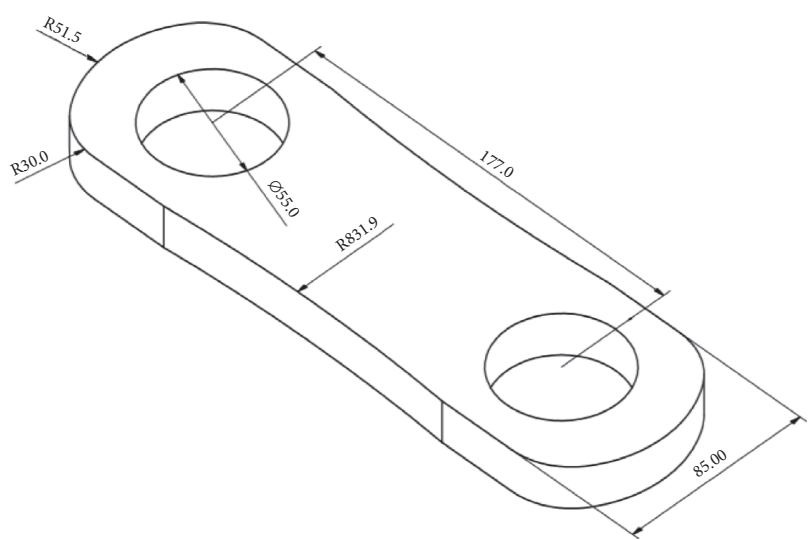

(d)

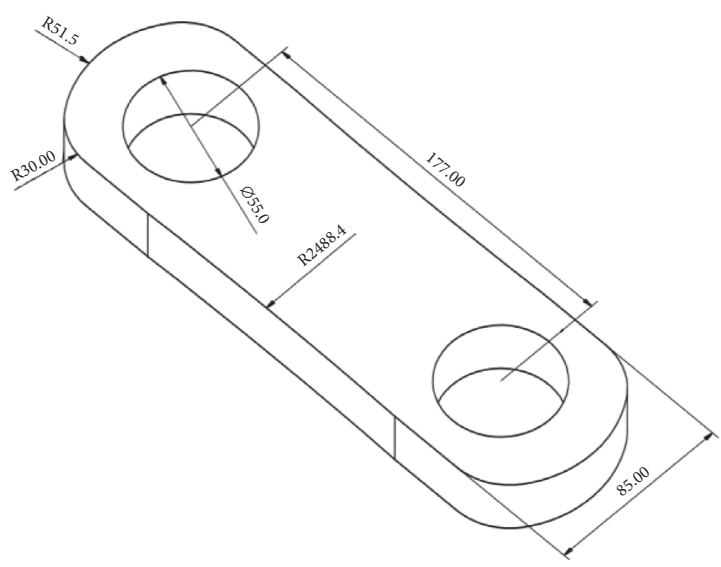

(f)

Figure 2: Conveyor chain link models: (a) $X=0 \mathrm{~mm}$, (b) $X=5 \mathrm{~mm}$, (c) $X=4 \mathrm{~mm}$, (d) $X=3 \mathrm{~mm}$, (e) $X=2 \mathrm{~mm}$, and (f) $X=1 \mathrm{~mm}$.

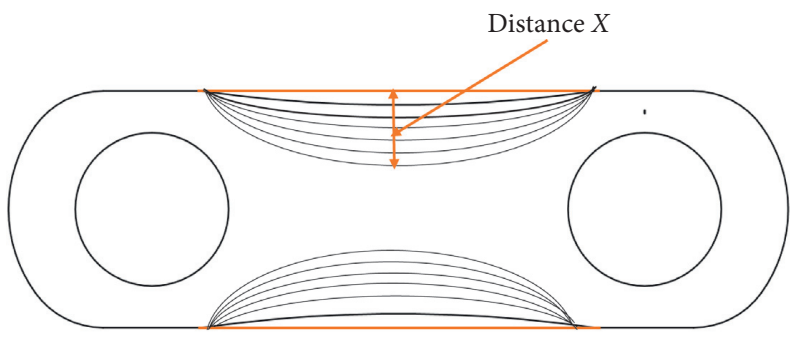

FIgURE 3: Varying distance $X$. 


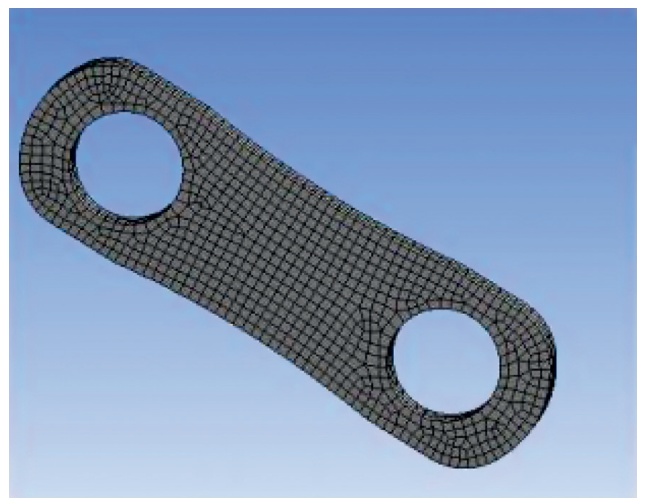

Figure 4: Meshed chain link.

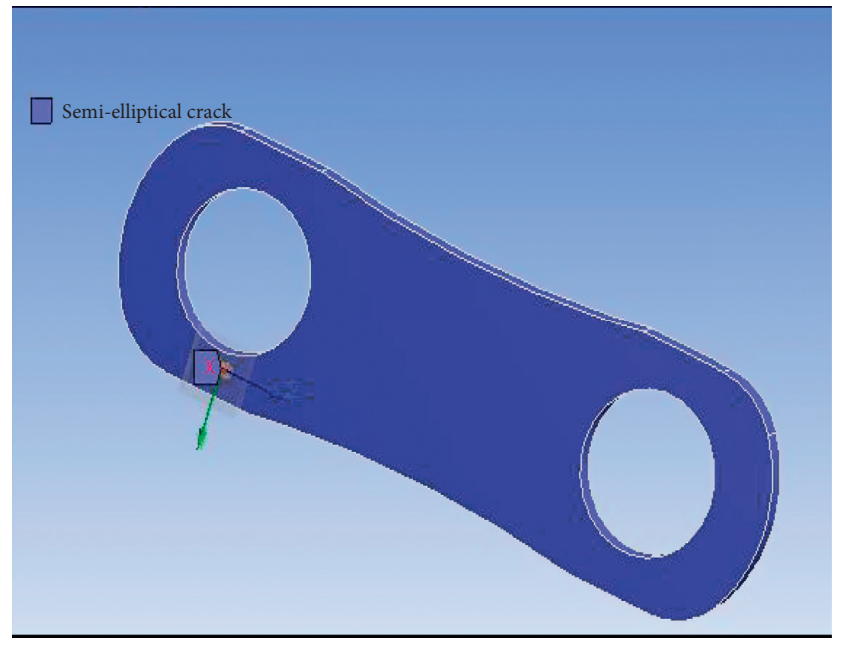

(a)

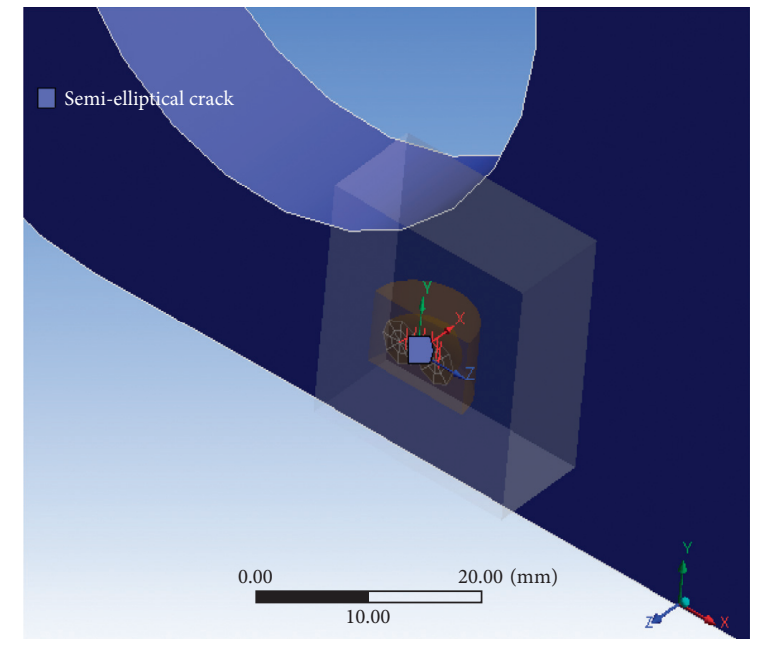

(b)

FIgURe 5: Modeled semielliptical crack: (a) semielliptical crack and (b) expanded view of semielliptical crack.

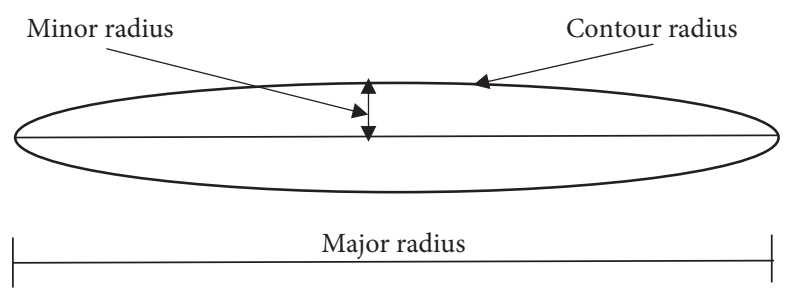

FIgURE 6: Semielliptical crack.

experimental results, it was observed that the optimal value of radius, thickness, and height was 44.5 to $45 \mathrm{~mm}, 9.5 \mathrm{~mm}$, and $68.30 \mathrm{~mm}$, respectively. It was concluded at the end of this research that the newly designed outer link of the conveyor chain saves $72 \mathrm{gm}$ of weight per link plate and $1.2 \mathrm{~kg}$ per meter length of chain.

Ravindra et al. [9] researched into various application aspects and manufacturing aspects to formulate an idea of the system. In addition, finite element analysis (FEA) was used to conduct shape optimization. Since lot of work has already been done on other components, the focus was narrowed down to specific component of chain which was the outer link. Different parameters of the outer link were changed, and subsequently, stress analysis was performed using ANSYS simulation software so as to establish whether material saving is possible or not. A conveyor chain with reduced weight was obtained by changing optimal radius and thickness of link plate, providing central hole in link plate as well as chamfering the circumference of link plate edge. Based on the outcome of the simulation, an optimal radius was obtained, thereby reducing the weight of the chain link which in turn reduced the cost of operation.

Sutar and Kondhalkar [11] carried out a research which focused on weight optimization of roller chain link inner 


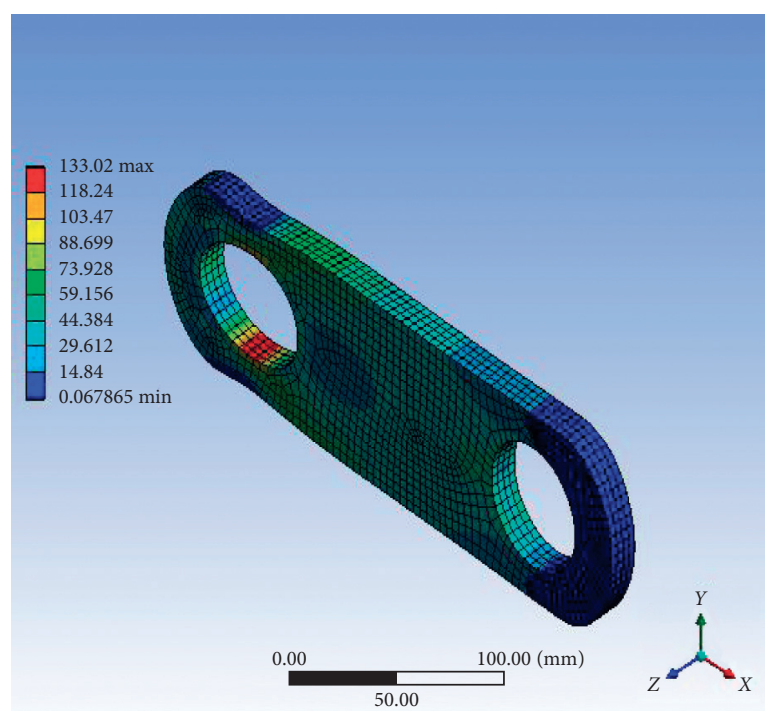

(a)

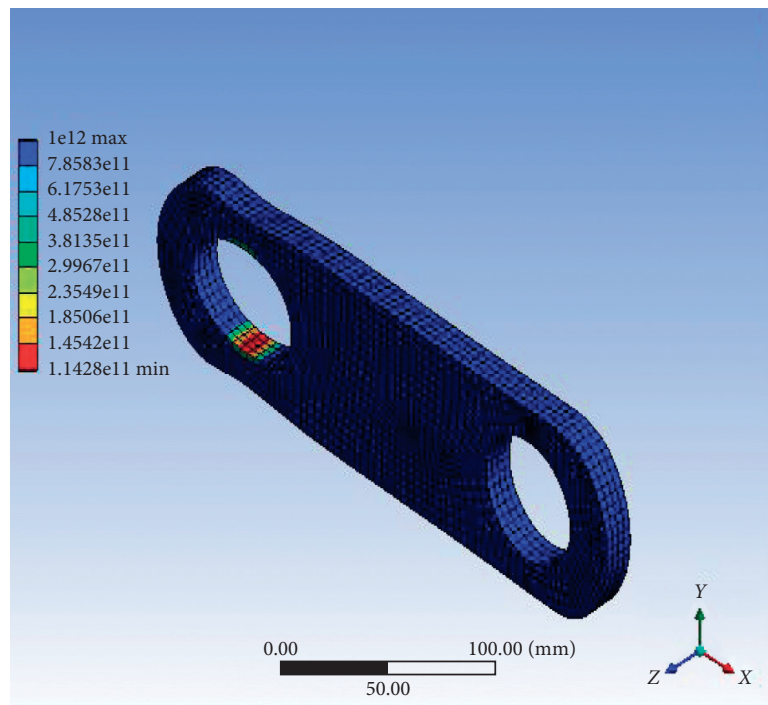

(c)

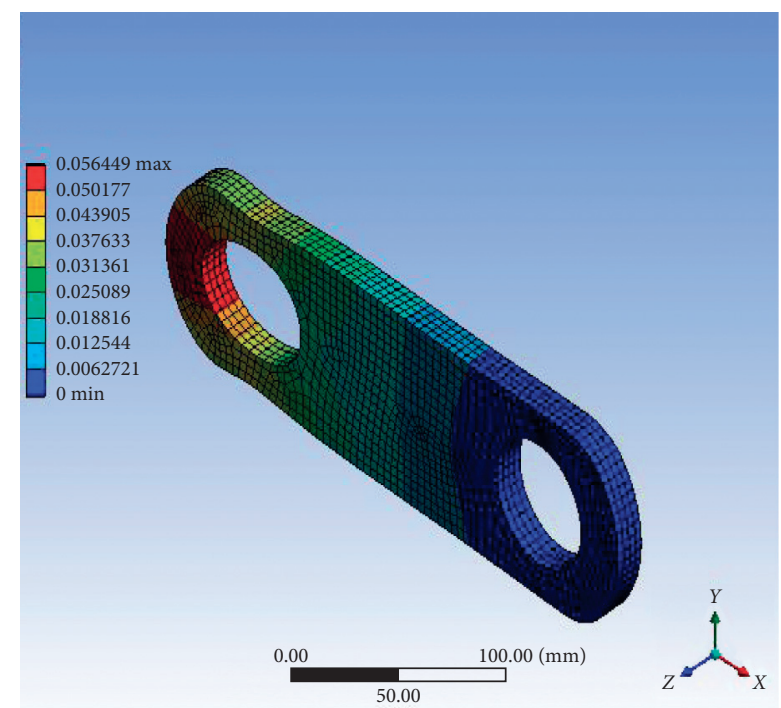

(b)

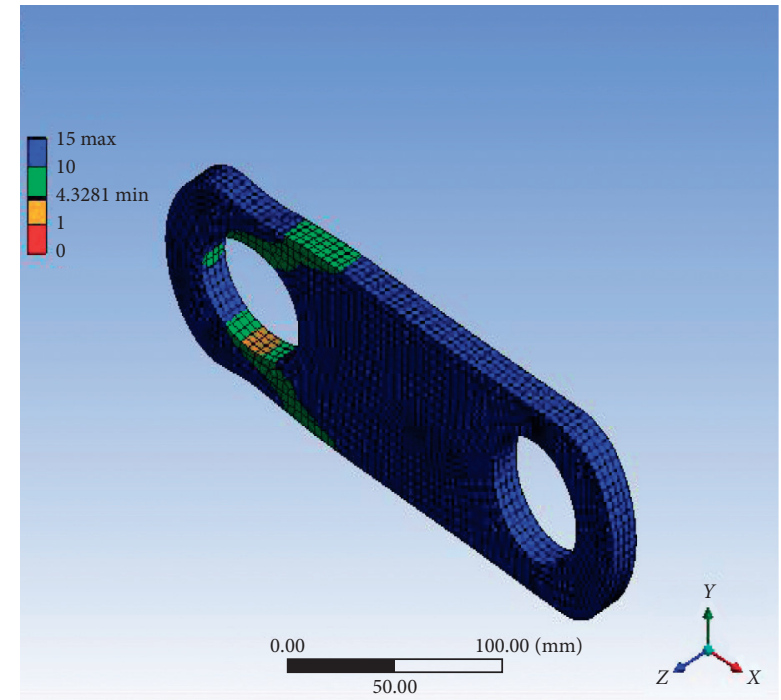

(d)

FigURE 7: Simulation results for chain link without a modeled crack with neck radius $0 \mathrm{~mm}(X=0)$ : (a) equivalent stress, (b) deformation, (c) fatigue life, and (d) safety factor.

plate by using shape optimization module in ANSYS workbench. By using the von Mises stress plot and shape finder plot, materials at the corners of the plate and a neck of optimal radius of value between 44.5 and $45 \mathrm{~mm}$ were removed as it was the least stressed regions of the chain link. The results obtained from the finite element analysis were within the $+/-10 \%$ of the calculated working stress, and therefore, the design was safe under the 25-ton maximum working load. Experimentally, the chain links failed at a load of 29.5 tons and beyond.

Noguchi et al. [12] proposed some methods of weight saving for roller chains. These methods were based on the finite element method (FEM) analysis of the stress and deformation in a link plate of a roller chain. Weight reduction was achieved by designing a model with a centrally located hole of diameters $3,4,5$, and $6 \mathrm{~mm}$ in the inner link plate and analyzed for stress. Chamfering edges of link plate circumference as well as reducing the thickness of the chain link were also considered. Stresses were 3\% higher in the proposed design, but the weight was reduced by $10 \%$. Tensile tests were performed on link plates made of resin, and the effectiveness of the proposed model was confirmed.

Bhosale and Patil [13] in their study proposed glass fiber reinforced polymer (GFRP) as an alternative material in the manufacturing of conveyor chain links so as to reduce the weight of the chain link, thereby reducing power consumption. Theoretical, finite element analysis (FEA) and experimental analysis were performed on the chain links. It was concluded that approximately $30.77 \%$ weight can be saved using GFRP material for the conveyor chain link 


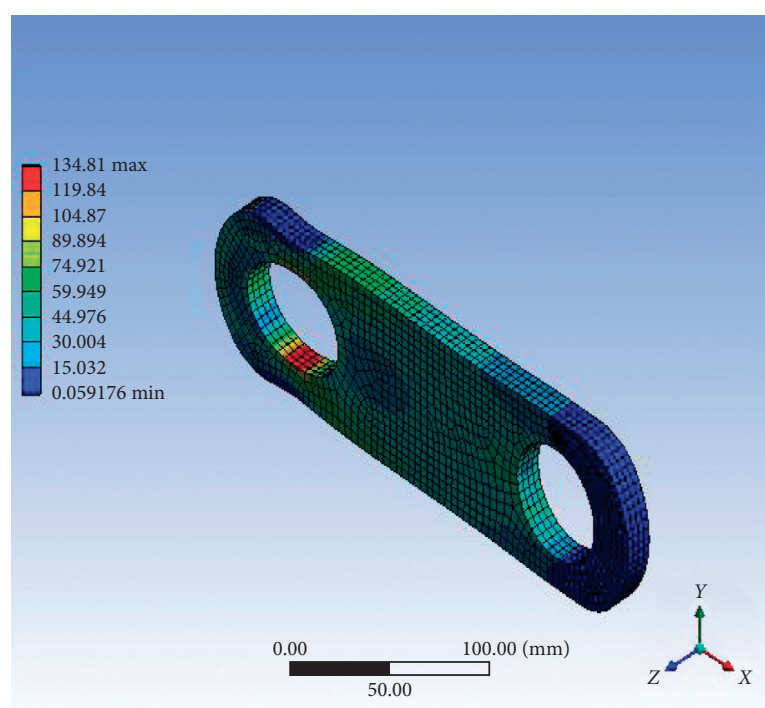

(a)

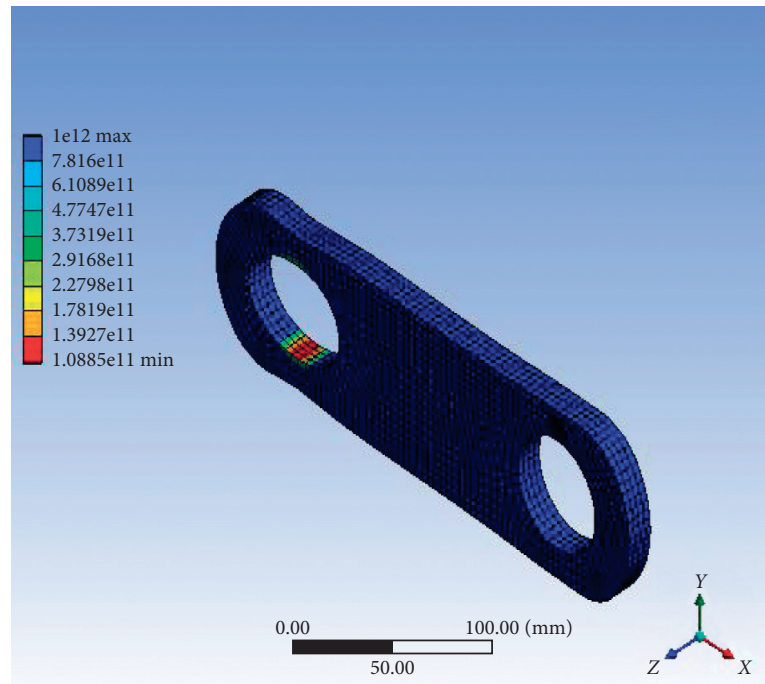

(c)

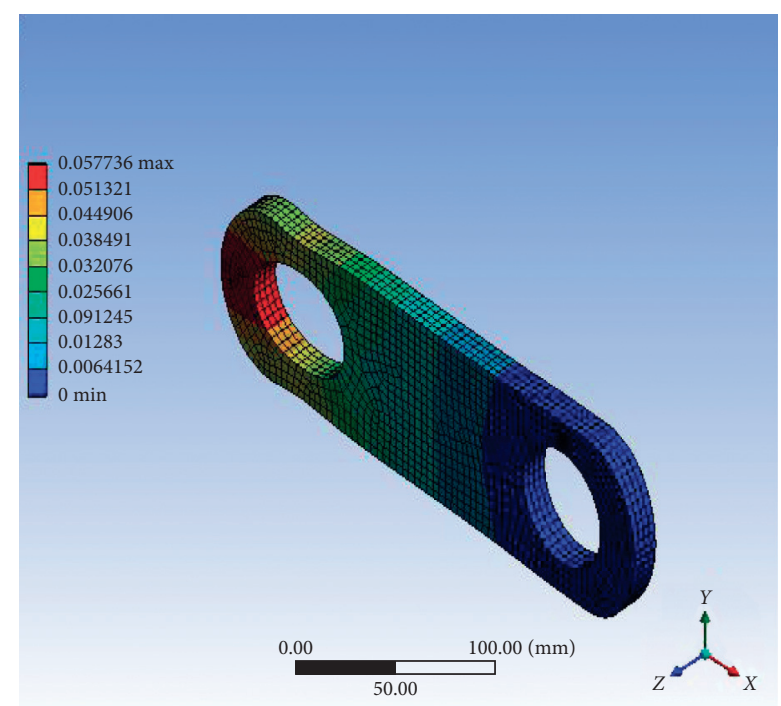

(b)

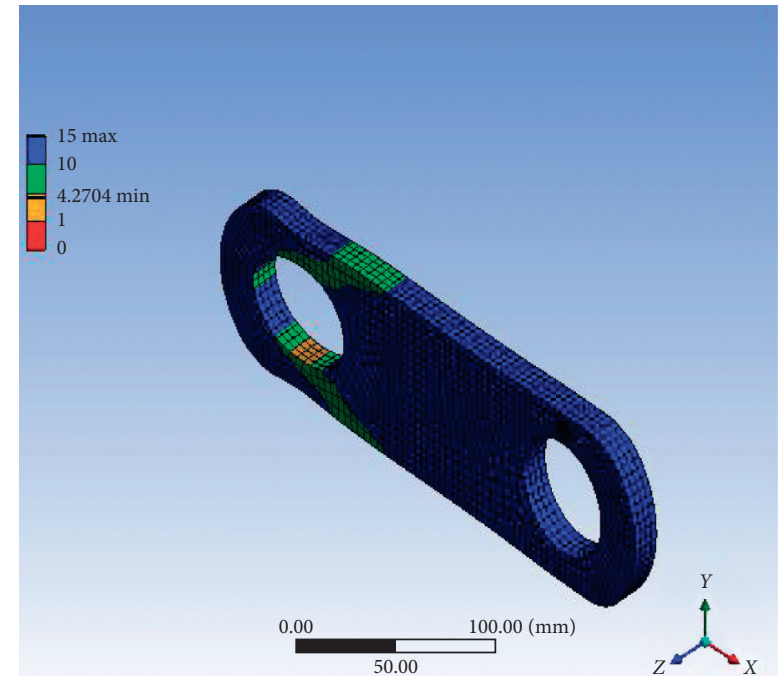

(d)

Figure 8: Simulation results for chain link without a modeled crack with neck radius $500 \mathrm{~mm}(X=1 \mathrm{~mm})$ : (a) equivalent stress, (b) deformation, (c) fatigue life, and (d) safety factor.

instead of conventional steel material. Also, the frequency of vibration was improved up to 1.2 times by replacing the current steel design with the GFRP material.

Kamble et al. [14] in their paper used topological approach to reduce the weight of chain link plate. Industrial factories such as sugar factories employ chain conveyors for many applications, and due to the bulky nature of stacker chain, power consumption is more. Topology optimization was, therefore, done using ANSYS software to reduce the power consumption rate. EN19 material was used for chain link plate for better strength. Area where stresses were low for applied loading was reduced by using software topology optimization. The weight of link plate after optimization reduced from $0.504 \mathrm{~kg}$ to $0.431 \mathrm{~kg}$, which resulted in $15 \%$ weight. Structural analysis was performed on the final design using ANSYS to find out maximum stresses in chain link plate. A computerized universal testing machine was used to obtain the breaking load of the newly designed chain link plate. The breaking load was in the range of $+/-10 \%$ of initial working load, and hence, new design was safe.

Shahane and Umbrajkaar [15] in their paper delved into various application aspects and manufacturing aspects to formulate an idea of the system. Finite element analysis (FEA) was used to conduct shape optimization. Since a lot of work had already been done on other components, in this paper, the focus has been narrowed down to a specific component of the outer link. A composite material was used for the outer chain link in order to reduce its weight. Weight of the link after optimization reduced from $0.3135 \mathrm{~kg}$ to 


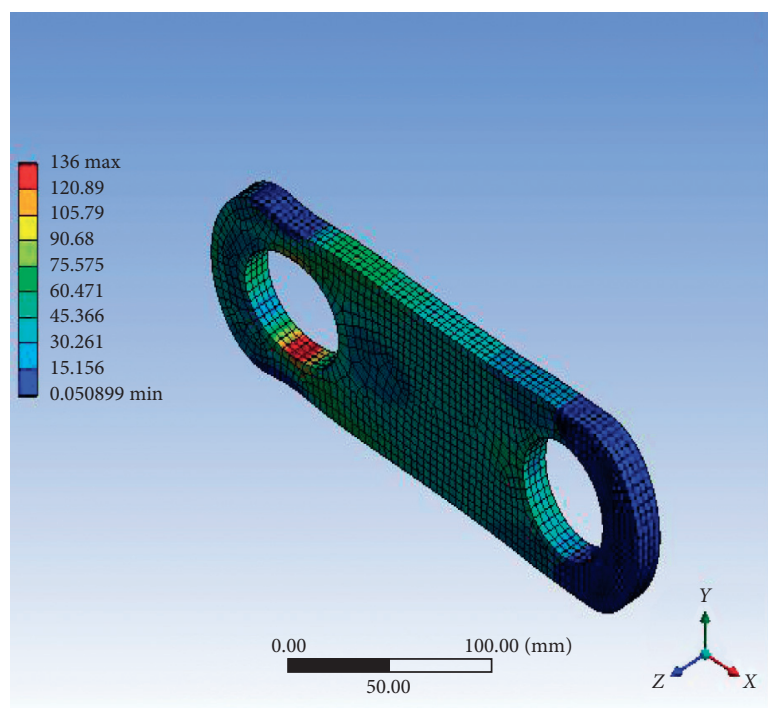

(a)

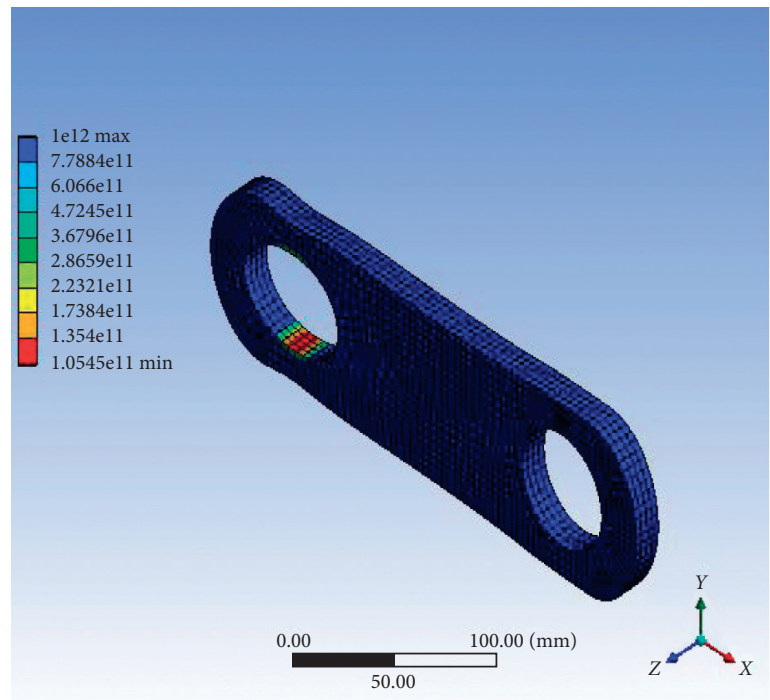

(c)

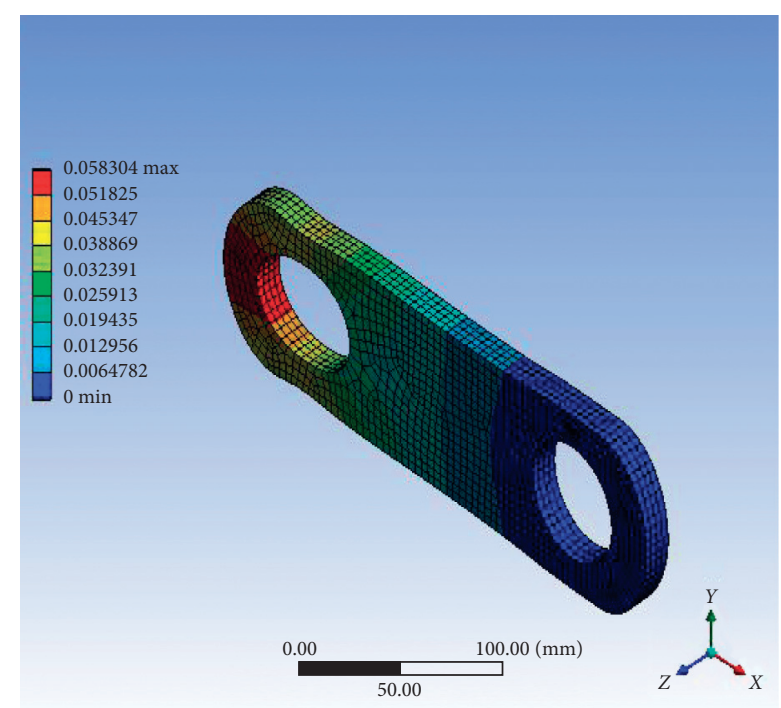

(b)

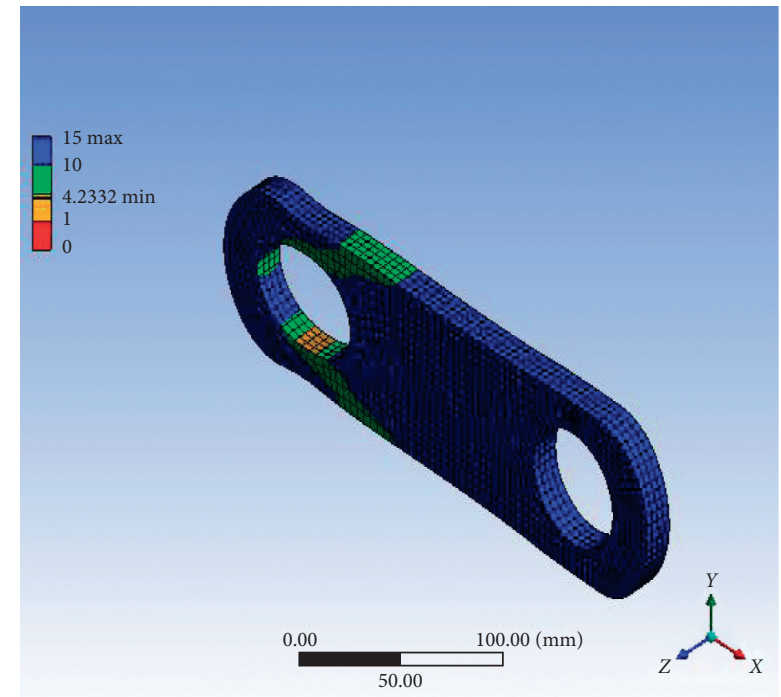

(d)

FIGURE 9: Simulation results for chain link without a modeled crack with neck radius $621.5 \mathrm{~mm}(X=2 \mathrm{~mm})$ : (a) equivalent stress, (b) deformation, (c) fatigue life, and (d) safety factor.

$0.2407 \mathrm{~kg}$. By using glass fiber material for the outer link, there was a reduction in weight of the outer link. The reduction in weight and maximum stress is obtained by using glass fiber as compared to original outer chain link.

2.1. Summary of Literature Review. Many researches have been carried on conveyor chain links in the area of weight reduction and stress analysis but fatigue analysis has never been considered. Also, finite element analysis (FEA) is seeen as an important tool for analysing conveyor chain links. The various literature studies on weight reduction never considered the effect of the neck on fatigue life. Yin et al. [3] in their paper established that inclusions are the root cause of failure of conveyor chain links, and therefore, testing conveyor chain links with modeled inclusion to predict its behavior is very crucial.

\section{Methodology}

CAD models were designed using Autodesk Inventor student software, and simulation was done using ANSYS academic software. The following procedure was carried out :

(1) First and foremost, the chain links were modeled to scale with accurate dimensions using Autodesk Inventor software as shown in Figure 2

The six models were obtained by varying the distance $X$ as shown in Figure 3 . The distance $X$ was reduced gradually by $1 \mathrm{~mm}$ from $5 \mathrm{~mm}$ to $0 \mathrm{~mm}$ to obtain six (6) models with different neck radii. This was done so as to predict the effect of the neck radius on the chain link.

The following were performed using the static structural analysis tool: 


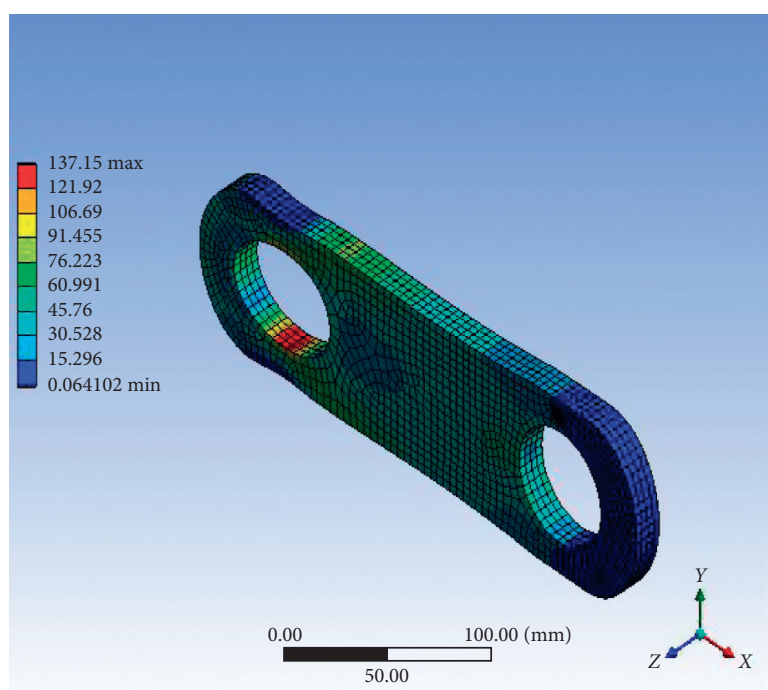

(a)

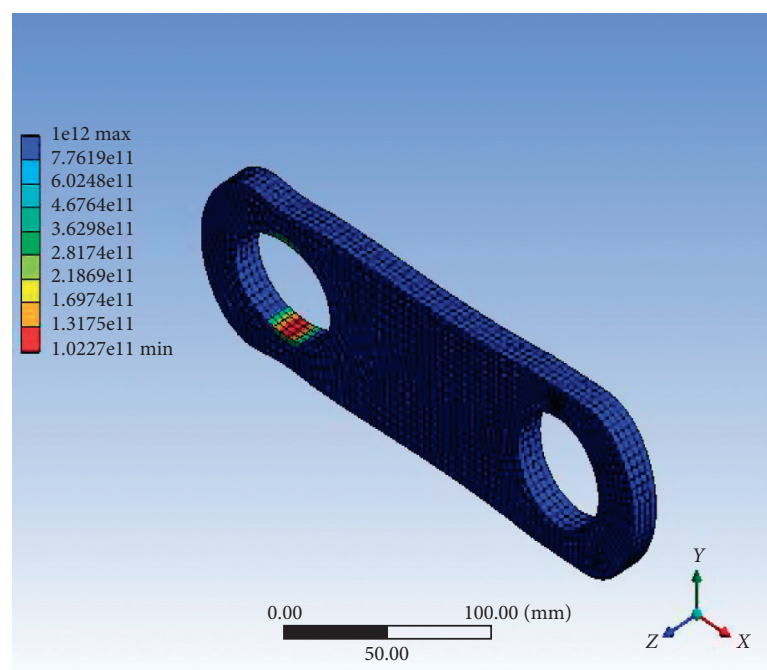

(c)

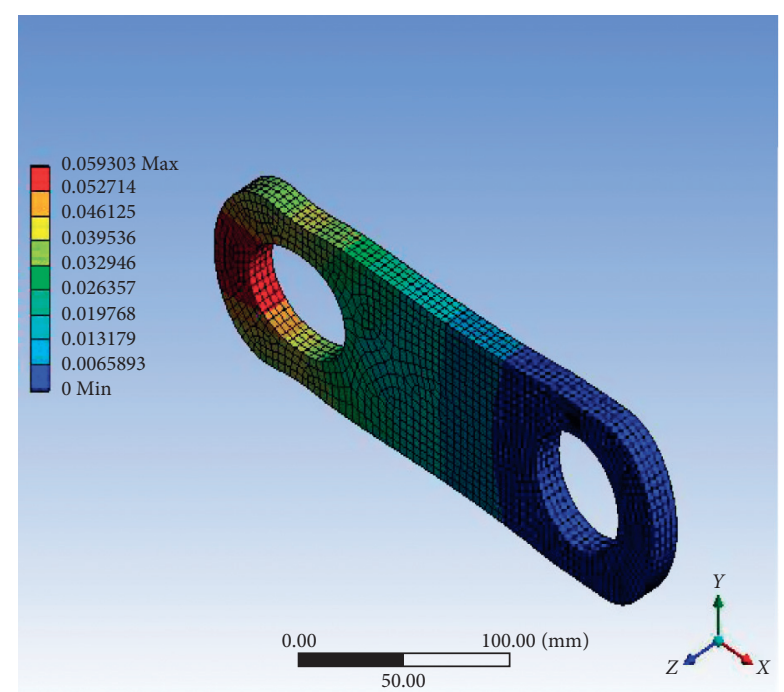

(b)

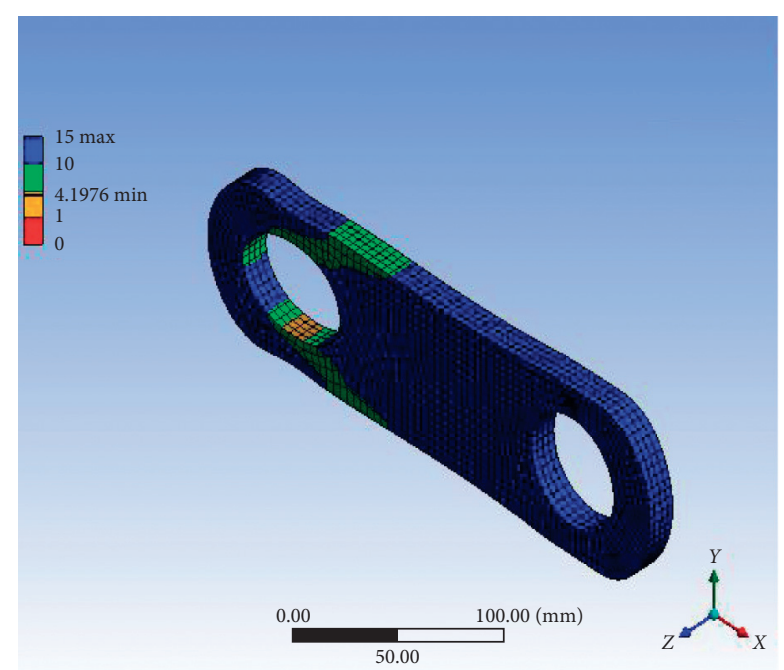

(d)

Figure 10: Simulation results for chain link without a modeled crack with neck radius $831.9 \mathrm{~mm}(X=3 \mathrm{~mm})$ : (a) equivalent stress, (b) deformation, (c) fatigue life, and (d) safety factor.

(2) Static structural analysis tool was used to perform the simulation on the chain link.

(3) The modeled chain links were firstly imported into ANSYS simulation software for simulation.

(4) The coordinates of the chain link were then set.

(5) The models were fine meshed as shown in Figure 4 so as to obtain accurate results. The number of elements used was 2199 with an element size of $5 \mathrm{~mm}$. The number of nodes were 12099.

(6) After meshing, static structural analysis was performed by applying the loads and boundary conditions on the chain link. The applied force was calculated using

$$
P=F v,
$$

where $P$ is the power rating, $F$ is the force, and $v$ is the linear velocity.

From the data collected, the power was $P=75 \mathrm{~kW}$ and velocity was $v=1.62 \mathrm{~m} / \mathrm{s}$. Therefore, from equation (1) the force was calculated as

$$
F=46.296 \mathrm{kN} \text {. }
$$

(7) The properties of the materials, i.e., Poisson's ratio (0.3), Young's modulus (210 GPa), density $\left(7850 \mathrm{k} \cdot \mathrm{g} \cdot \mathrm{m}^{-3}\right)$, and tensile strength $(600 \mathrm{kN})$ were then imputed [16]. These data were obtained from the manufacturer of the bucket elevator conveyor chain links at East African Portland Cement.

(8) Equivalent stress and deformation were then inserted into the solution tree and then simulated to obtain the results. 


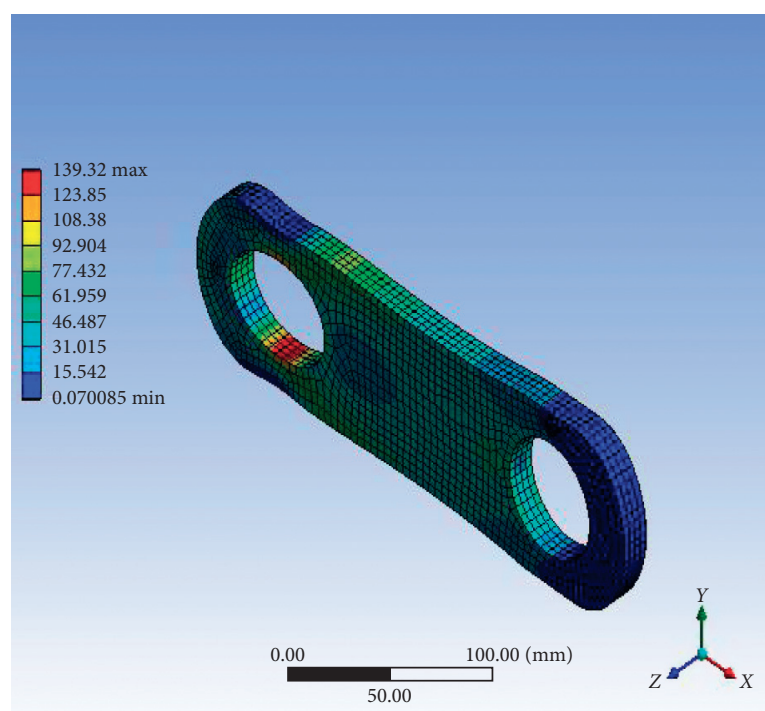

(a)

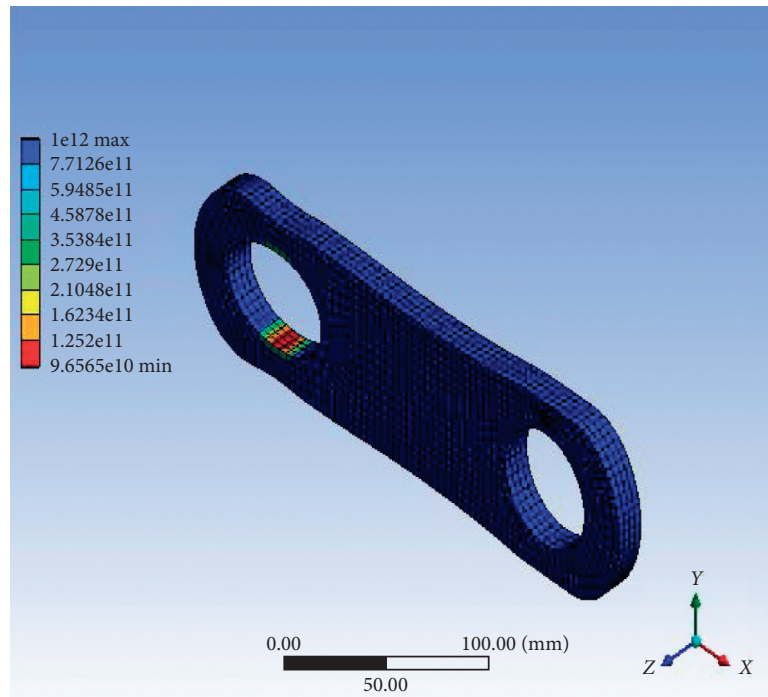

(c)

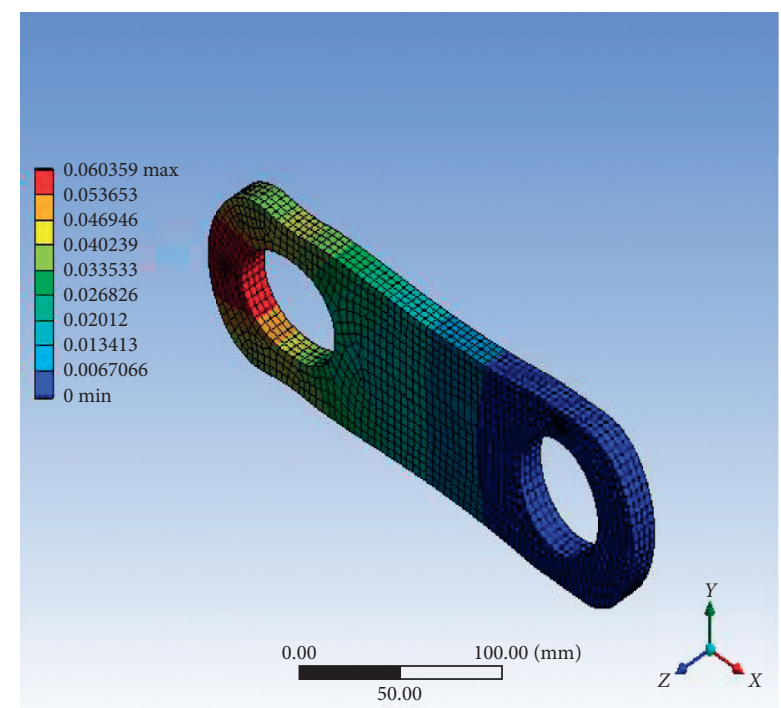

(b)

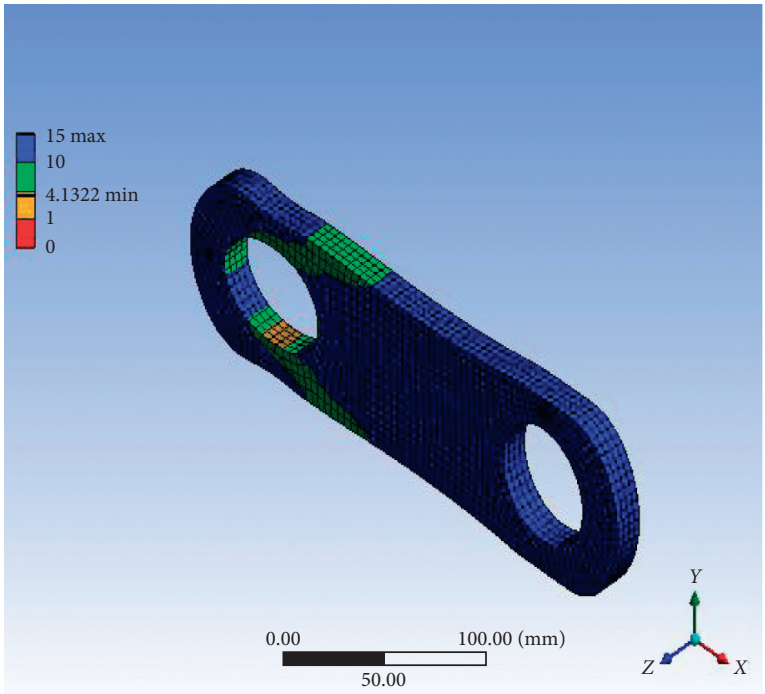

(d)

FIGURE 11: Simulation results for chain link without a modeled crack with neck radius $1245.5 \mathrm{~mm}(X=4 \mathrm{~mm})$ : (a) equivalent stress, (b) deformation, (c) fatigue life, and (d) safety factor.

(9) Fatigue tool was then inserted in the solution tree and used to obtain the fatigue life and safety factor by running the simulation. The failure theory that was used was the Goodman theory of failure because it is a better predictor of failure than the other theories since it is linear, simple to use, and more conservative [17].

(10) The same procedure was again repeated for the six (6) different chain links, but this time after meshing, a semielliptical crack was modeled into the chain link as shown in Figure 5. The semielliptical crack was introduced as a model for the inclusion which from the experimental results was known to be the cause of failure. The major radius, minor radius, and contour radius are 2,1 , and $3 \mathrm{~mm}$, respectively.

(11) The modeled crack is as shown in Figure 6.

\section{Results}

The results and discussions were presented in two factions: first of all, the simulation results for the chain link without a modeled crack and then with a modeled crack.

\subsection{Results for Designed Chain Link without a Modeled Crack.} Figure 7 shows the results obtained from the simulation of the chain link without a modeled crack with neck radius of $0 \mathrm{~mm}$ (with no neck). The equivalent stress, deformation, fatigue life, and safety factor were obtained as $135 \mathrm{MPa}, 0.05645 \mathrm{~mm}, 1.143 \times 10^{11}$ cycles, and 4.33, respectively.

The results obtained from the simulation of the chain link without a modeled crack with neck radius of $500 \mathrm{~mm}$ are as shown in Figure 8. The equivalent stress, 


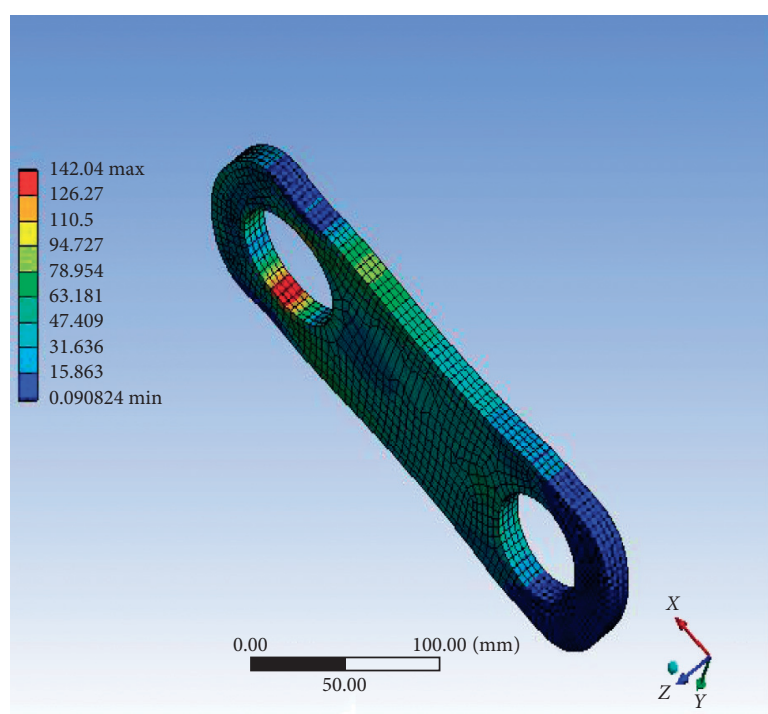

(a)

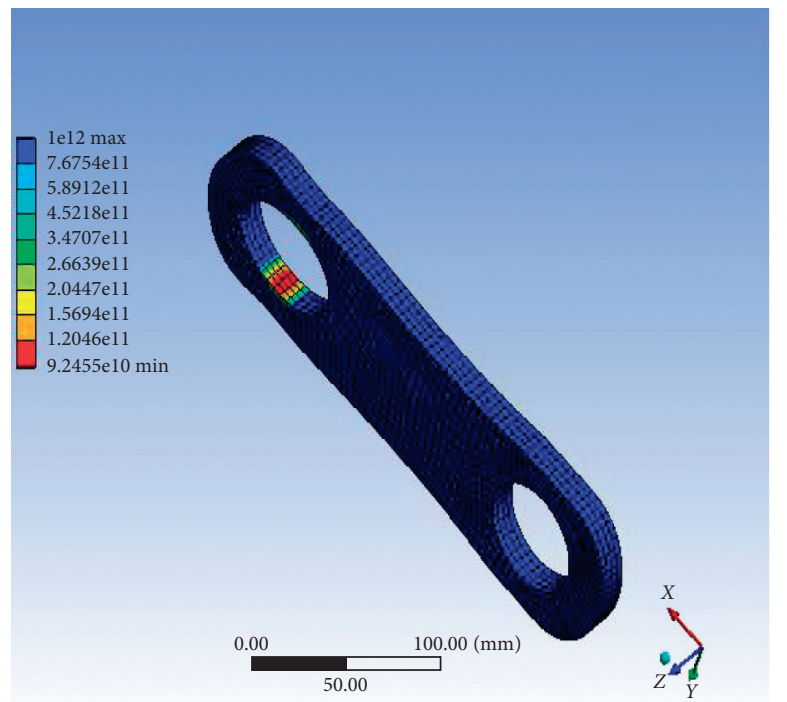

(c)

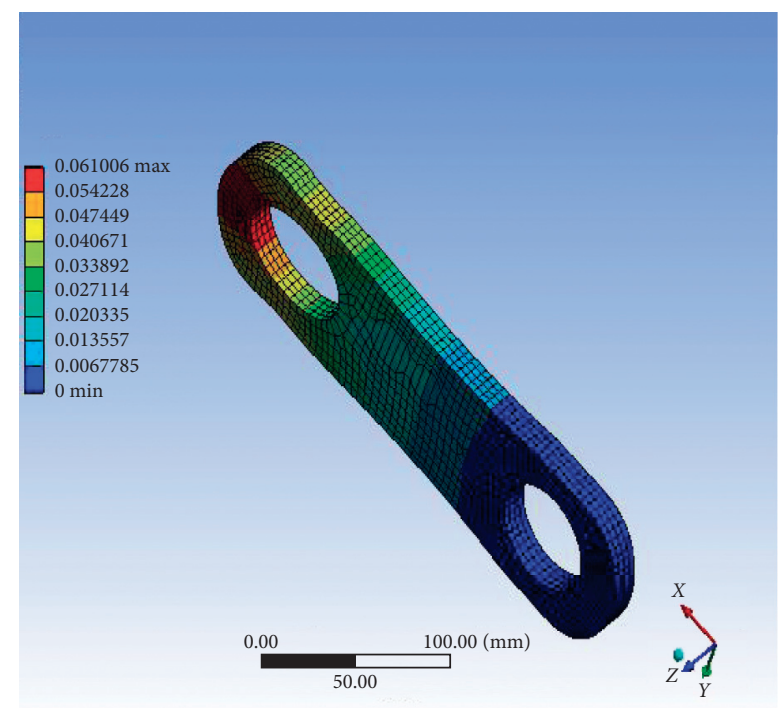

(b)

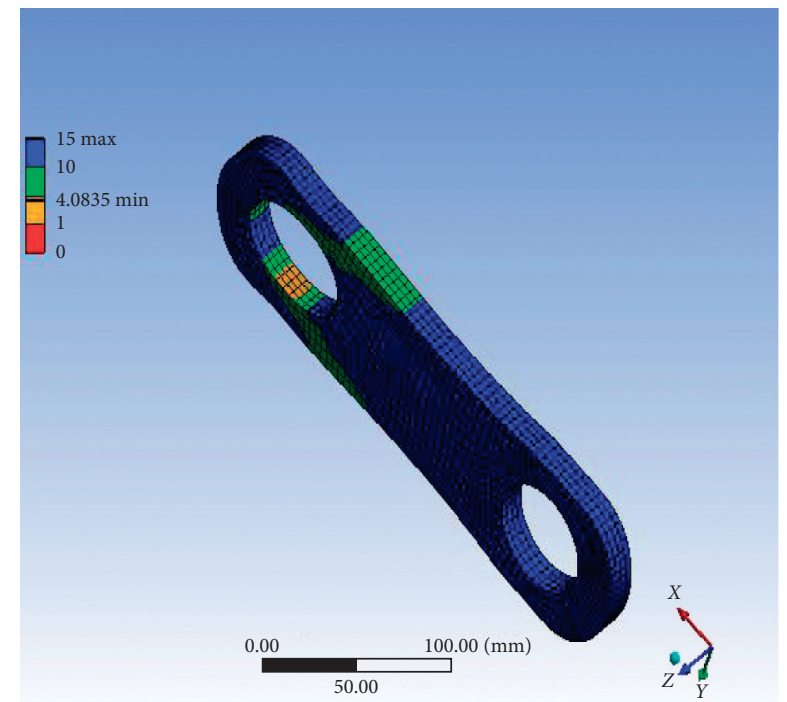

(d)

FIGURE 12: Simulation results for chain link without a modeled crack with neck radius $2488.4 \mathrm{~mm}(X=5 \mathrm{~mm})$ : (a) equivalent stress, (b) deformation, (c) fatigue life, and (d) safety factor.

deformation, fatigue life, and safety factor were obtained as $139 \mathrm{MPa}, \quad 0.05774 \mathrm{~mm}, \quad 1.088 \times 10^{11}$ cycles, and 4.27 , respectively.

Figure 9 shows the results obtained from the simulation of the chain link without a modeled crack with neck radius of $621.5 \mathrm{~mm}$. The equivalent stress, deformation, fatigue life, and safety factor were found to be $141 \mathrm{MPa}, 0.05830 \mathrm{~mm}$, $1.055 \times 10^{11}$ cycles, and 4.23 , respectively.

The results obtained from the simulation of the chain link without a modeled crack with neck radius of $831.9 \mathrm{~mm}$ are as shown in Figure 10. The equivalent stress, deformation, fatigue life, and safety factor were obtained to be $142 \mathrm{MPa}, 0.05930 \mathrm{~mm}$, $1.022 \times 10^{11}$ cycles, and 4.19, respectively.

Figure 11 shows the results obtained from the simulation of the chain link without a modeled crack with neck radius of
$1245.5 \mathrm{~mm}$. The equivalent stress, deformation, fatigue life, and safety factor were found to be $144 \mathrm{MPa}, 0.06035 \mathrm{~mm}$, $9.6565 \times 10^{10}$ cycles, and 4.13 , respectively.

The results obtained from the simulation of the chain link without a modeled crack with neck radii of $2488.4 \mathrm{~mm}$ are as shown in Figure 12. The equivalent stress, deformation, fatigue life, and safety factor were obtained as $145 \mathrm{MPa}, 0.06101 \mathrm{~mm}, 9.25 \times 10^{10}$ cycles, and 4.08 .

4.2. Results for Designed Chain Link with a Modeled Crack. The following results were obtained from the simulation of designed chain links with a modeled crack. The modeled crack was located around the neck region. The equivalent stress, deformation, fatigue life, and safety factor were 


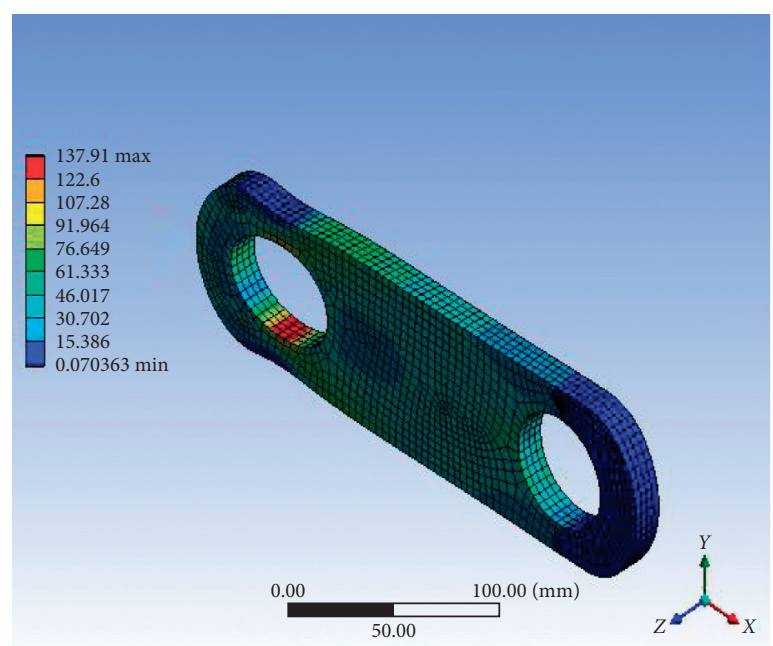

(a)

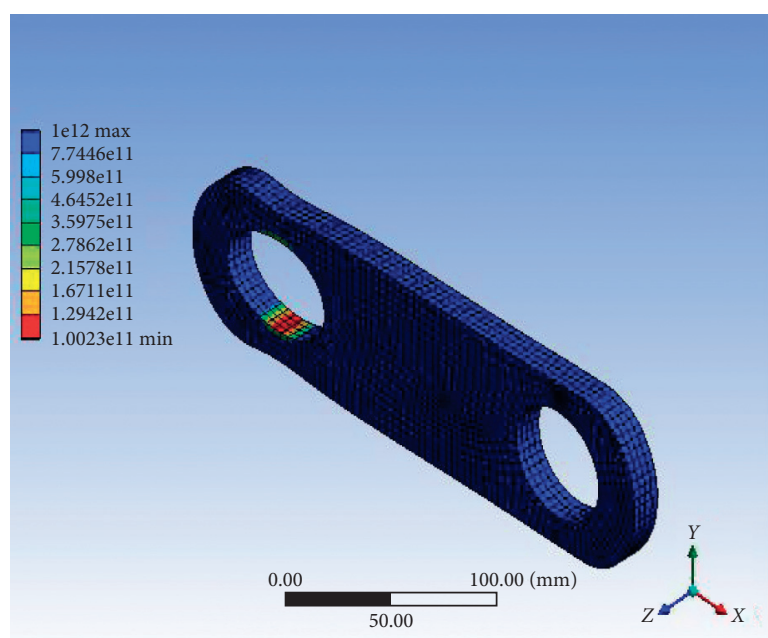

(c)

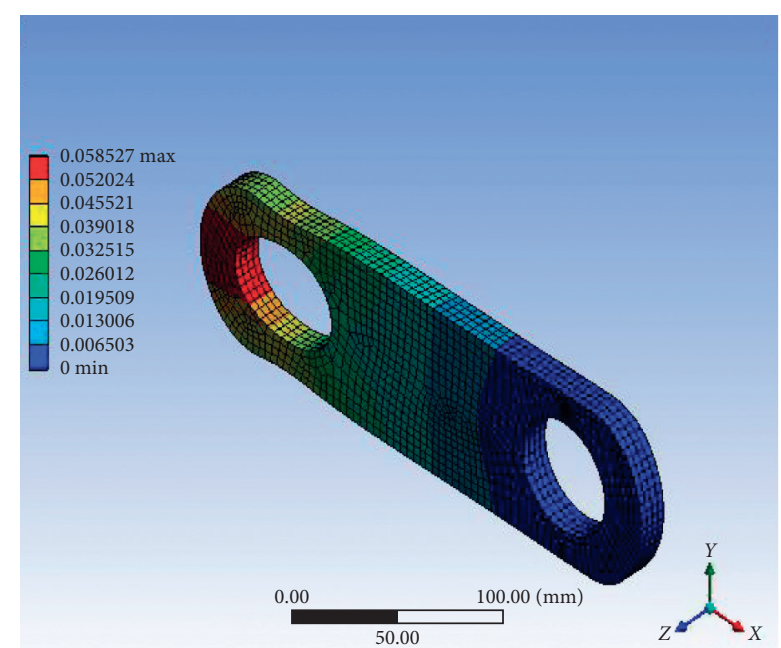

(b)

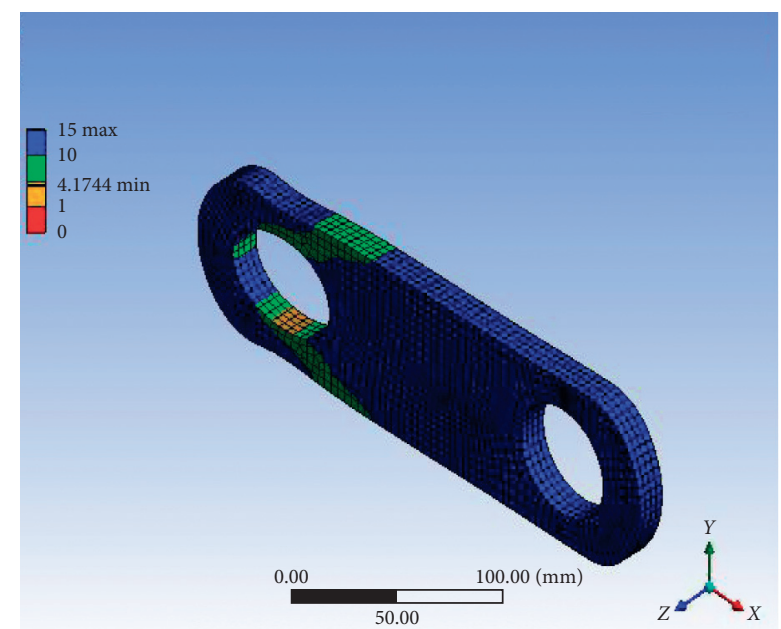

(d)

Figure 13: Simulation results for chain link with a modeled crack and neck radius $0 \mathrm{~mm}(X=0 \mathrm{~mm})$ : (a) equivalent stress, (b) deformation, (c) fatigue life, and (d) safety factor.

obtained using ANSYS simulation software. The crack was introduced as a model for the inclusions so as to predict the effects of inclusions on the chain link.

Figure 13 shows the results obtained from the simulation of the chain link with a modeled crack with neck radius of $0 \mathrm{~mm}$. The equivalent stress, deformation, fatigue life, and safety factor were obtained as $133 \mathrm{MPa}, 0.05852 \mathrm{~mm}$, $1.008 \times 10^{11}$ cycles, and 4.17 , respectively.

The results obtained from the simulation of the chain link with a modeled crack with neck radius of $500 \mathrm{~mm}$ are as shown in Figure 14. The equivalent stress, deformation, fatigue life, and safety factor were obtained as $135 \mathrm{MPa}$, $0.05947 \mathrm{~mm}, 9.774 \times 10^{10}$ cycles, and 4.145 , respectively.

Figure 15 shows the results obtained from the simulation of the chain link with a modeled crack with neck radius of
$621.5 \mathrm{~mm}$. The equivalent stress, deformation, fatigue life, and safety factor were obtained as $136 \mathrm{MPa}, 0.06045 \mathrm{~mm}$, $9.241 \times 10^{10}$ cycles, and 4.08, respectively.

The results obtained from the simulation of the chain link with a modeled crack with neck radius of $831.9 \mathrm{~mm}$ are as shown in Figure 16. The equivalent stress, deformation, fatigue life, and safety factor were obtained as $137 \mathrm{MPa}$, $0.06148 \mathrm{~mm}, 8.959 \times 10^{10}$ cycles, and 4.19 , respectively.

Figure 17 shows the results obtained from the simulation of the chain link with a modeled crack with neck radius of $1245.5 \mathrm{~mm}$. The equivalent stress, deformation, fatigue life, and safety factor were obtained as $139 \mathrm{MPa}, 0.06245 \mathrm{~mm}$, $8.522 \times 10^{10}$ cycles, and 3.99 , respectively.

The results obtained from the simulation of the chain link with a modeled crack with a neck radius of $24884 \mathrm{~mm}$ are as 


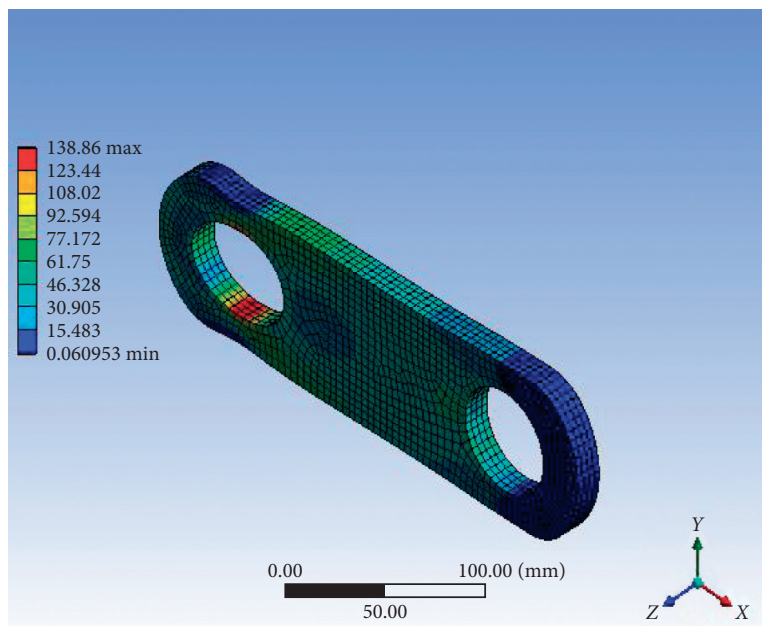

(a)

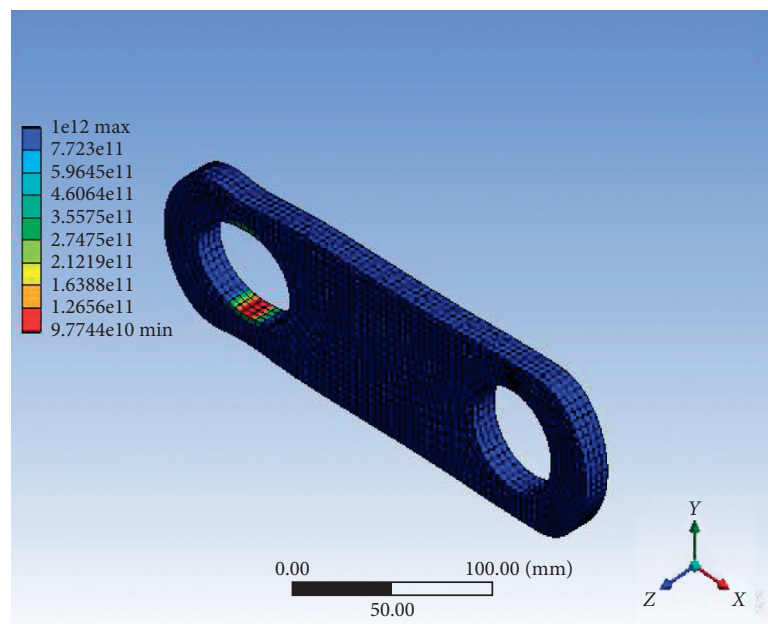

(c)

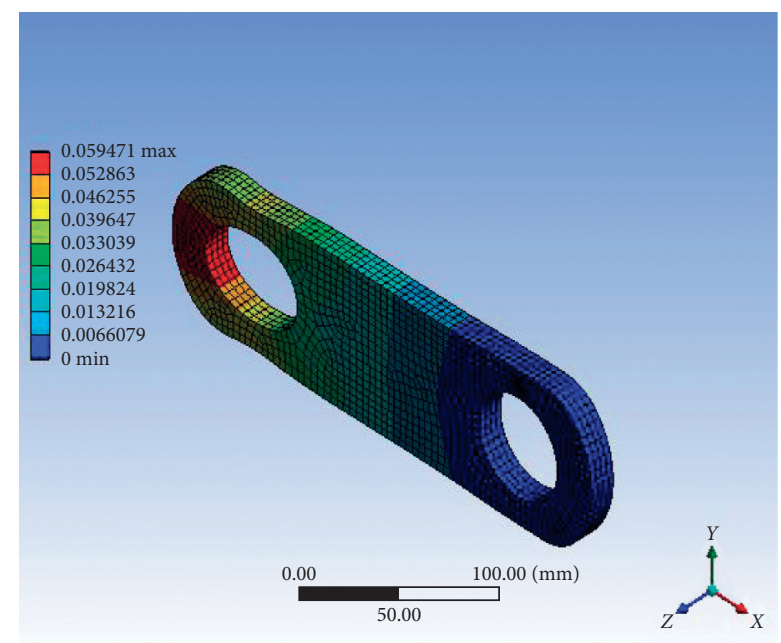

(b)

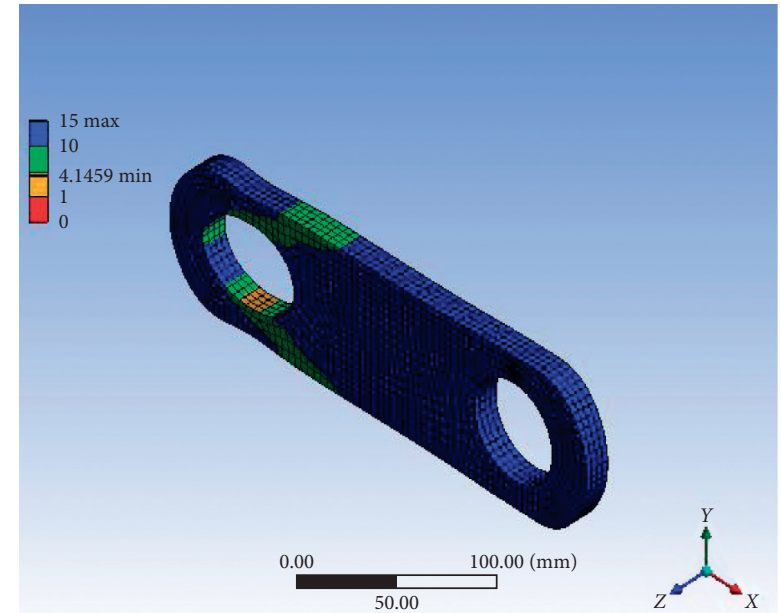

(d)

FIGURE 14: Simulation results for chain link with a modeled crack and neck radius $500 \mathrm{~mm}(X=1 \mathrm{~mm})$ : (a) equivalent stress, (b) deformation, (c) fatigue life, and (d) safety factor.

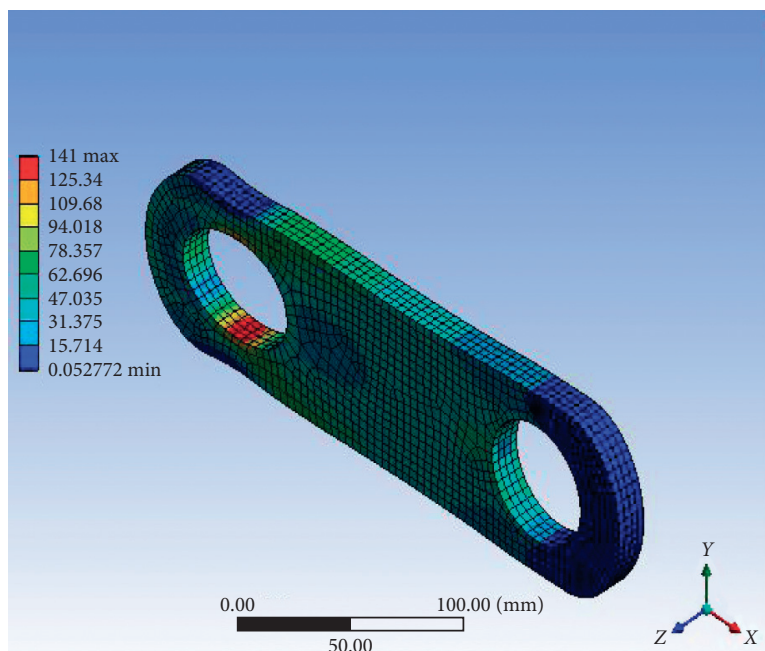

(a)

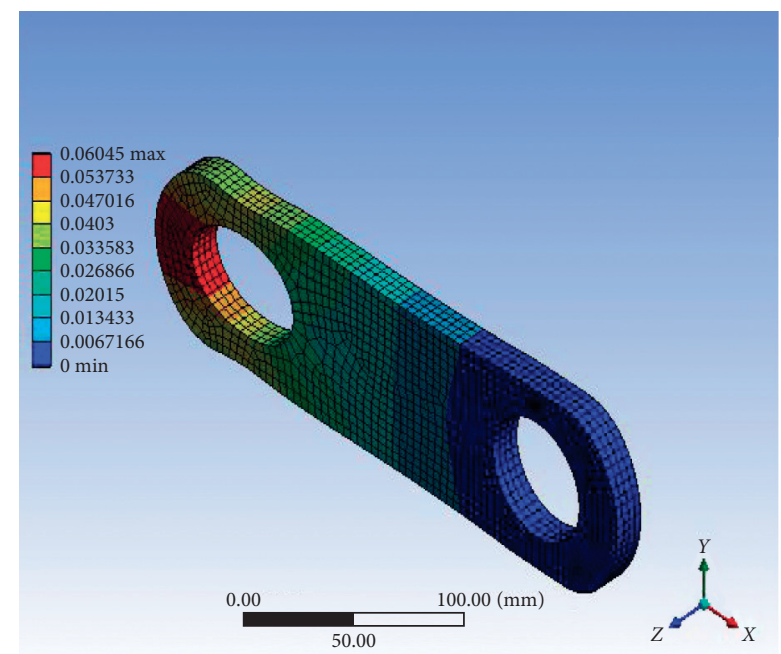

(b)

FIgURE 15: Continued. 


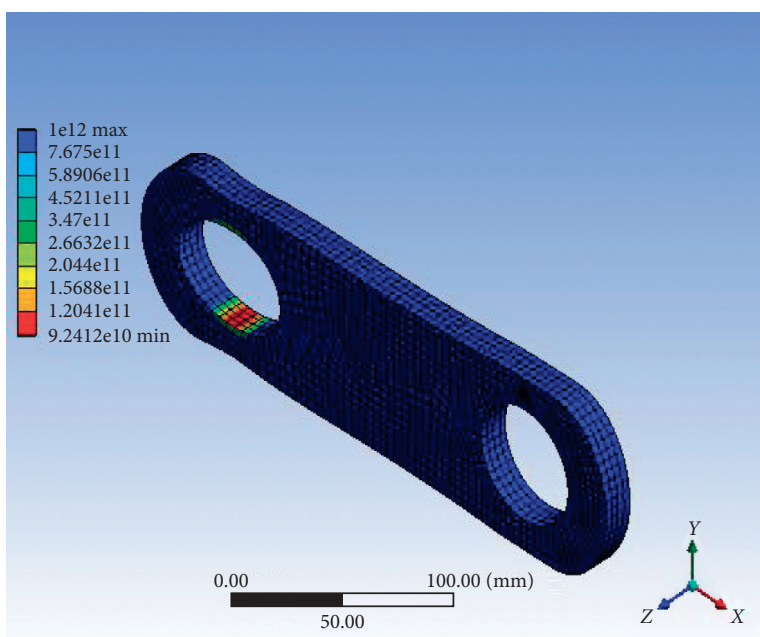

(c)

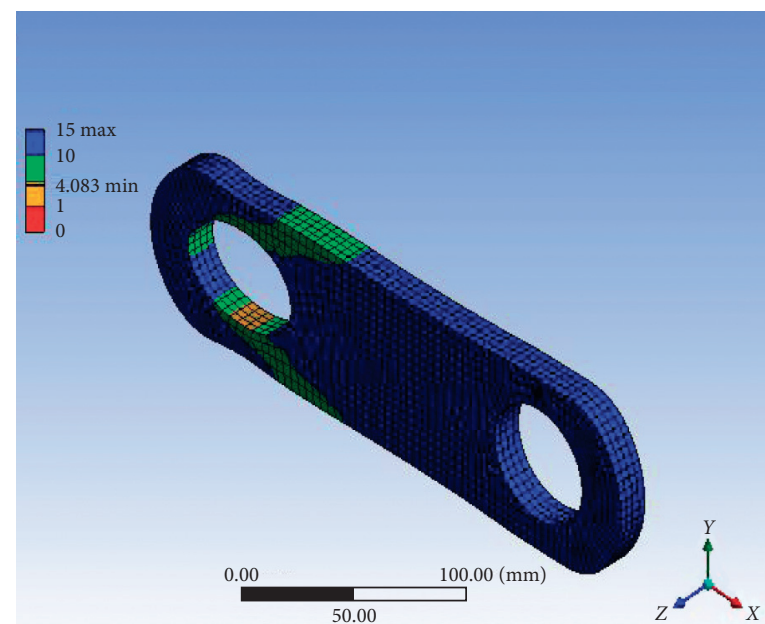

(d)

Figure 15: Simulation results for chain link with a modeled crack and neck radius $621.5 \mathrm{~mm}(X=2 \mathrm{~mm})$ : (a) equivalent stress, (b) deformation, (c) fatigue life, and (d) safety factor.

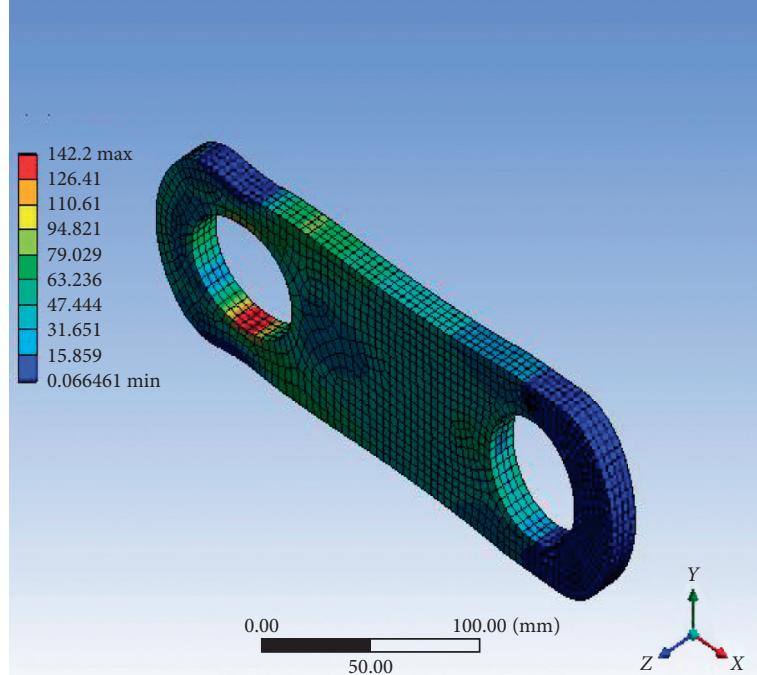

(a)

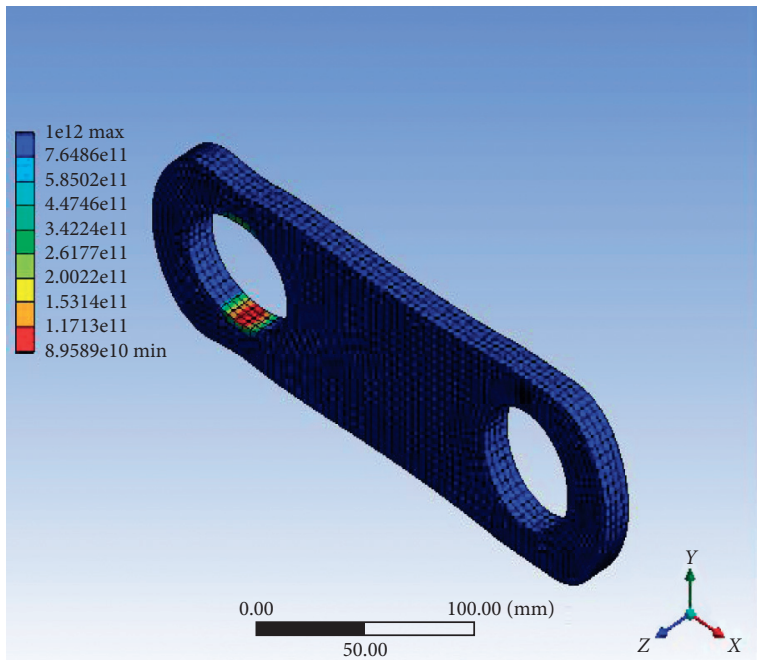

(c)

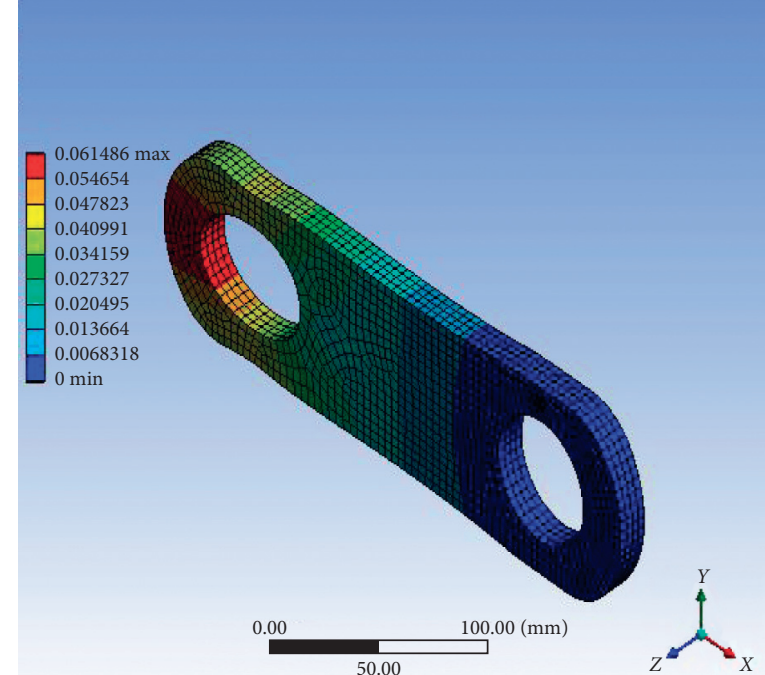

(b)

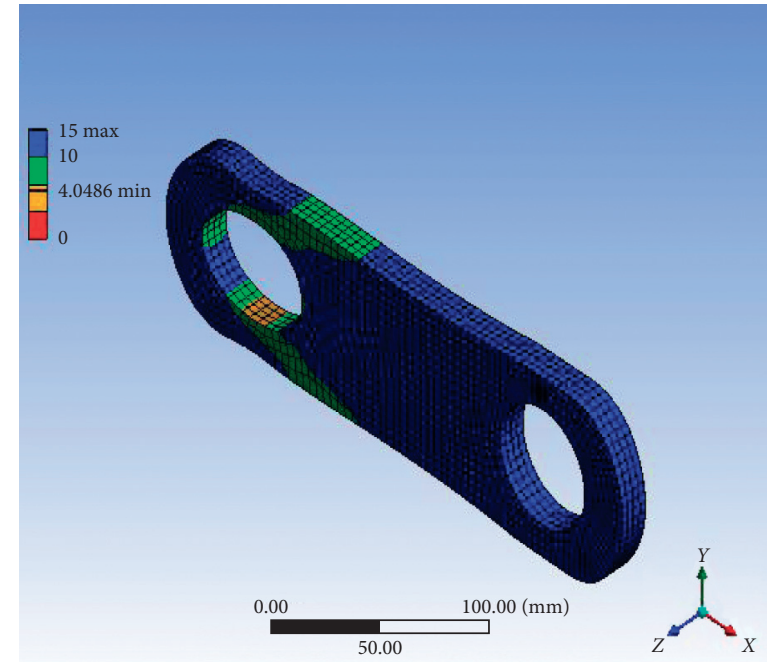

(d)

FIGURE 16: Simulation results for chain link with a modeled crack and neck radius $831.9 \mathrm{~mm}(X=3 \mathrm{~mm})$ : (a) equivalent stress, (b) deformation, (c) fatigue life, and (d) safety factor. 


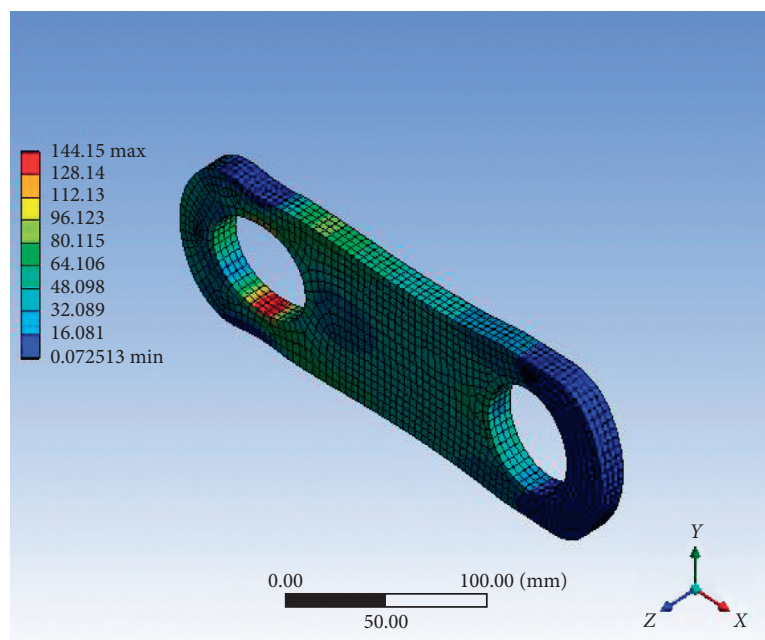

(a)

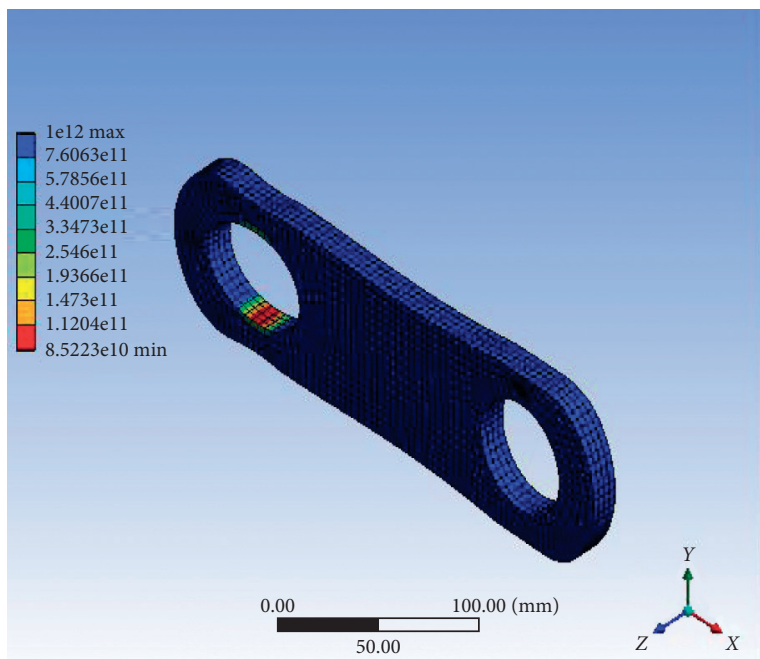

(c)

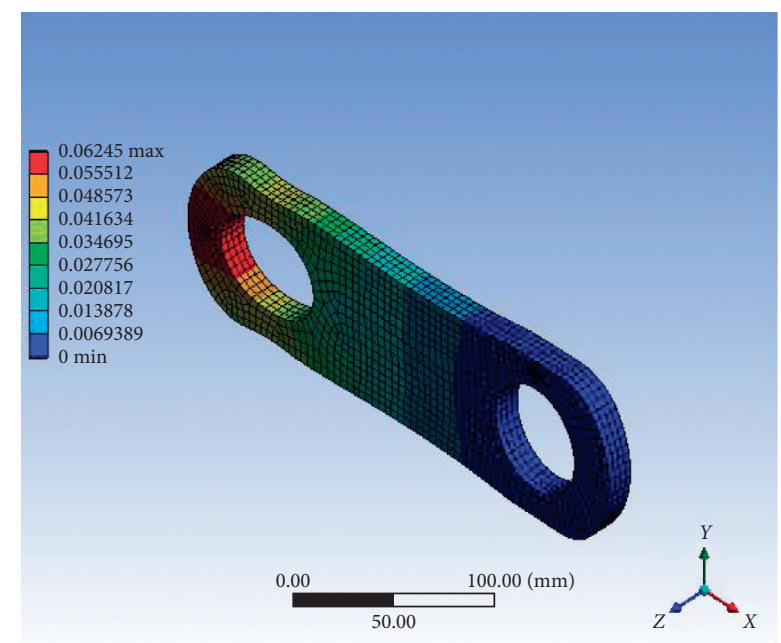

(b)

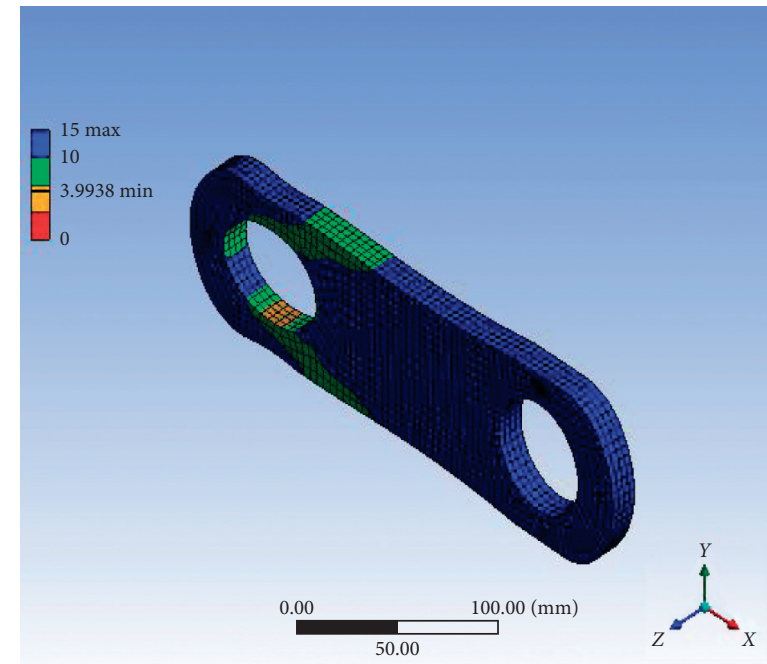

(d)

Figure 17: Simulation results for chain link with a modeled crack and neck radius $1245.5 \mathrm{~mm}(X=4 \mathrm{~mm})$ : (a) equivalent stress, (b) deformation, (c) fatigue life, and (d) safety factor.

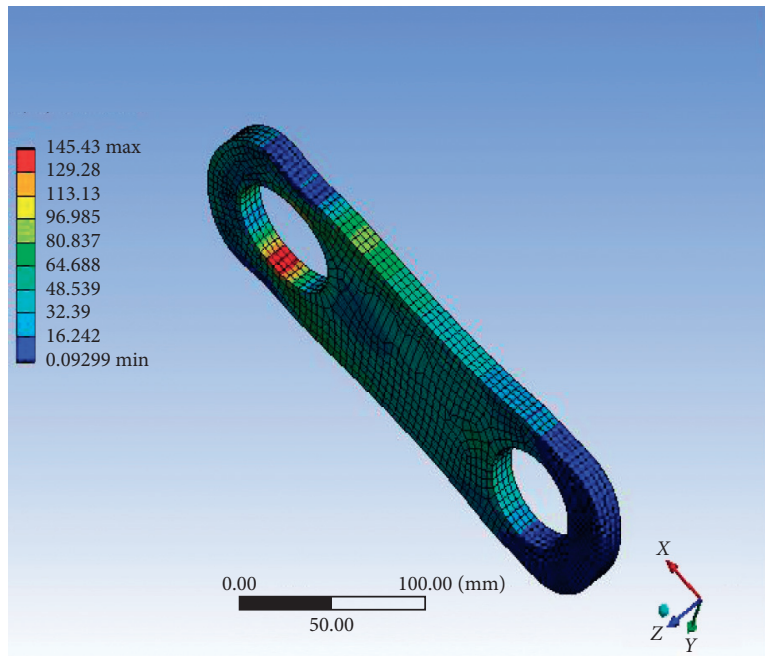

(a)

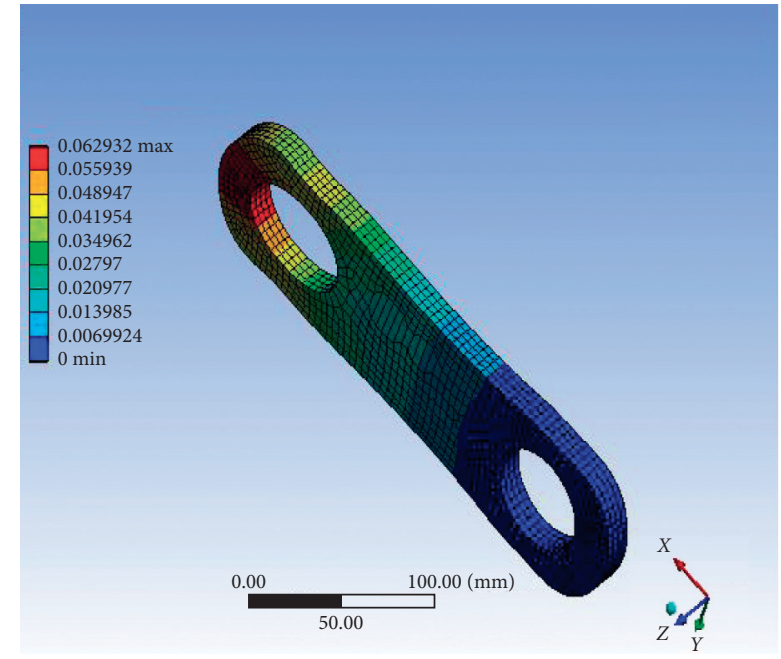

(b)

FIgURe 18: Continued. 


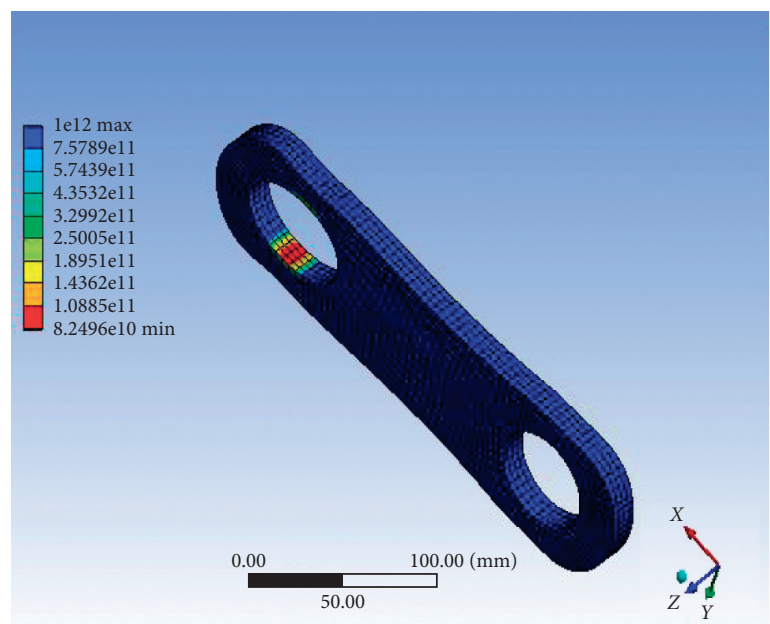

(c)

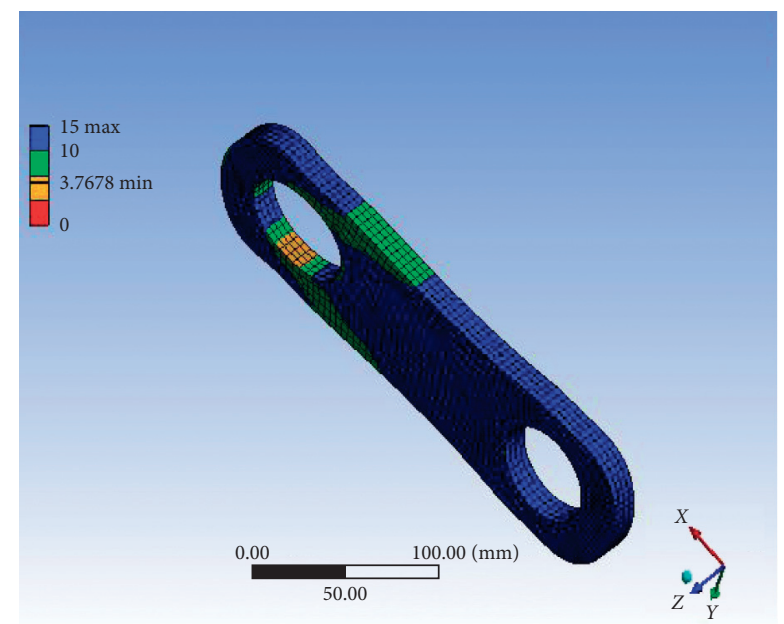

(d)

Figure 18: Simulation results for chain link with a modeled crack and neck radius $2488.4 \mathrm{~mm}(X=5 \mathrm{~mm})$ : (a) equivalent stress, (b) deformation, (c) fatigue life, and (d) safety factor.

TABLE 1: Results obtained for the chain link without a modeled crack.

\begin{tabular}{lccc}
\hline Distance $X(\mathrm{~mm})$ & Equivalent stress $(\mathrm{MPa})$ & Deformation $(\mathrm{mm})$ & Fatigue life $($ cycles $)$ \\
\hline 0 & 133 & 0.05644 & $1.14 \times 10^{11}$ \\
1 & 135 & 0.05744 & $1.09 \times 10^{11}$ \\
2 & 136 & 0.05830 & $1.05 \times 11^{11}$ \\
3 & 137 & 0.05930 & $1.02 \times 10^{11}$ \\
4 & 139 & 0.06036 & $9.66 \times 10^{10}$ \\
5 & 142 & 0.06101 & $9.25 \times 10^{10}$ \\
\hline
\end{tabular}

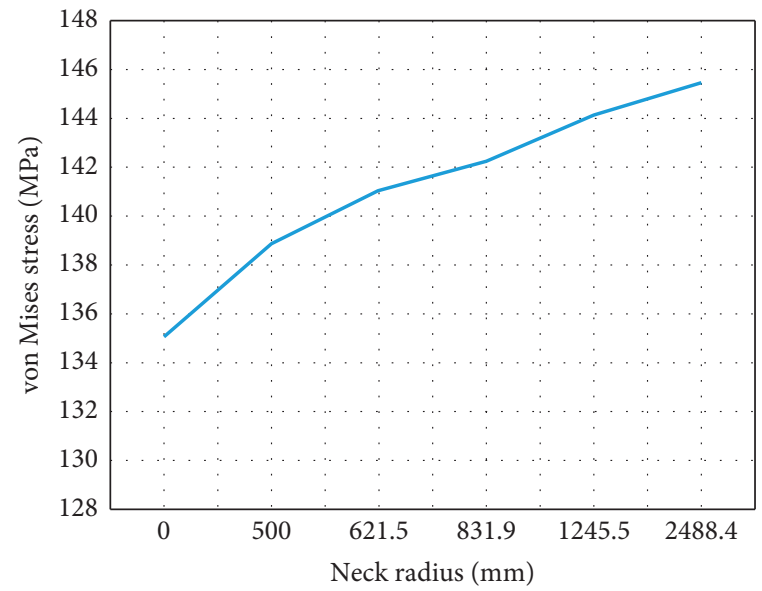

(a)

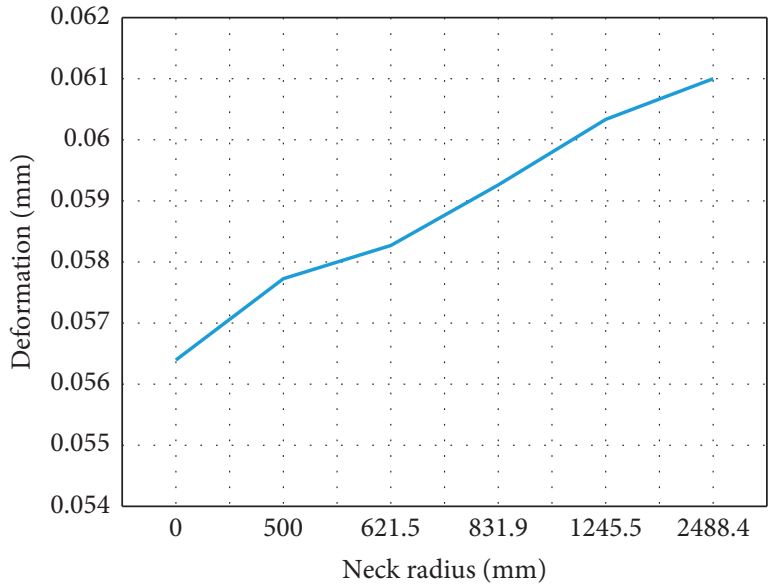

(b)

Figure 19: Continued. 


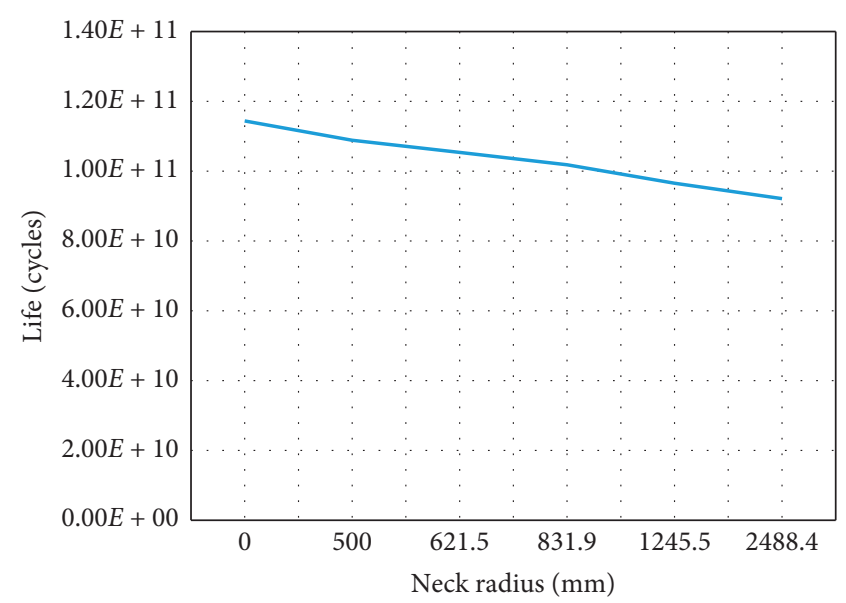

(c)

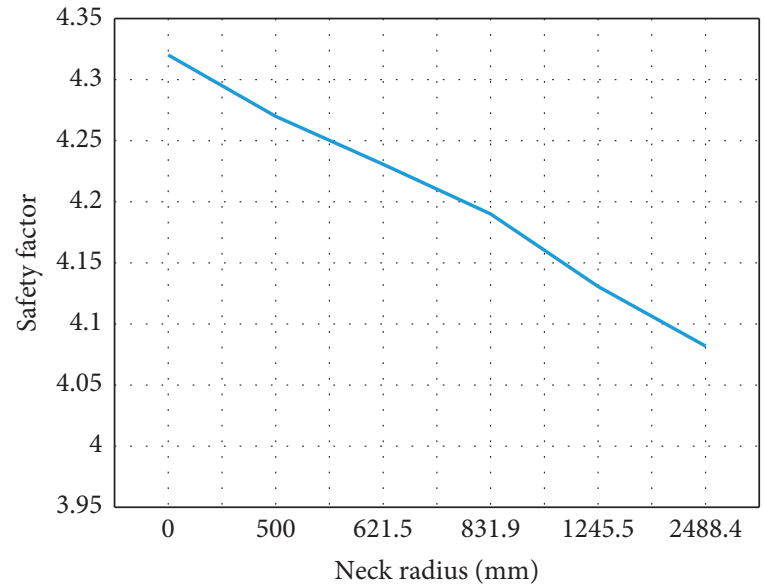

(d)

Figure 19: A graph of results for designs with different neck radii and without modeled crack.

TABLE 2: Results obtained for chain link with a modeled crack.

\begin{tabular}{|c|c|c|c|c|}
\hline$X(\mathrm{~mm})$ & Equivalent stress $(\mathrm{MPa})$ & Deformation $(\mathrm{mm})$ & Fatigue life (cycles) & Safety factor \\
\hline 0 & 135 & 0.05731 & $1.01 \times 10^{11}$ & 4.26 \\
\hline 1 & 139 & 0.05947 & $9.77 \times 10^{10}$ & 4.15 \\
\hline 2 & 141 & 0.06045 & $9.24 \times 10^{10}$ & 4.08 \\
\hline 3 & 142 & 0.06148 & $8.96 \times 10^{10}$ & 4.04 \\
\hline 4 & 144 & 0.06148 & $8.52 \times 10^{10}$ & 3.99 \\
\hline 5 & 145 & 0.06301 & $8.25 \times 10^{10}$ & 3.77 \\
\hline
\end{tabular}

shown in Figure 18. The equivalent stress, deformation, fatigue life, and safety factor were obtained as $142 \mathrm{MPa}, 0.06293 \mathrm{~mm}$, $8.249 \times 10^{10}$ cycles, and 3.767, respectively.

\section{Discussion}

The results obtained from simulation for the different designs with different neck radii without a modeled crack are tabulated as shown in Table 1 . As the neck radius (distance $X$ ) increased from 0 to $5 \mathrm{~mm}$, the equivalent stress also increased from 135 to $145 \mathrm{MPa}$ because the neck acts as a stress raiser. The deformation also increased from $0.05644 \mathrm{~mm}$ to $0.06101 \mathrm{~mm}$ because of the increase in equivalent stress. However, the fatigue life and the safety factor decreased from $1.14 \times 10^{11}$ to $9.25 \times 10^{10}$ and 4.32 to 4.08 , respectively. This observation was also as a result of the equivalent stress increasing. The area of stress concentration was around the hole and therefore the conveyor chain link is likely to fail in that region.

The results obtained for the chain link without a modeled crack are as shown in Table 1.

Figure 19 shows graphs comparing the equivalent stress, deformation, fatigue life, and safety factor for the designs with different neck radii without a modeled crack. From the graphs, it can be seen that as the neck radius increases, the equivalent stress and deformation also increase, but the fatigue life and safety factor decrease. It was observed that the higher the equivalent stress, the lower the fatigue life and safety factor, but the higher the deformation. It can, therefore, be concluded that the design with no neck, i.e., $X=0 \mathrm{~mm}$, or no necking showed better performance.

The results obtained from simulation for the different designs with different neck radii with a modeled crack are tabulated as shown in Table 2. As the neck radius (distance $X$ ) increased from o $\mathrm{mm}$ to 24884 , the equivalent stress increased from 133 to $142 \mathrm{MPa}$ because the neck radius act as a stress raiser. The increase in equivalent stress resulted in increase in deformation from $0.05731 \mathrm{~mm}$ to 0.06301 , a reduction in fatigue life from $1.01 \times 10^{11}$ to $8.25 \times 10^{10}$, and reduction in safety factor from 4.26 to 3.77 .

The results obtained for chain link with a modeled crack are as summarized in Table 2.

Figure 20 shows graphs comparing the equivalent stress, deformation, fatigue life, and safety factor for the designs with different neck radii with a modeled crack. From the graphs, it can be seen that as the neck radius increases, the equivalent stress and deformation also increase but the fatigue life and safety factor decreased. The observation made was that the higher the equivalent stress, the lower the fatigue life and safety factor, but the higher the deformation. It can, therefore, be concluded that the design with no neck, i.e., $0 \mathrm{~mm}$ neck radius is a better option compared to the others. The new design shows an improvement on equivalent stress, deformation, fatigue life, and safety factor in comparison with the existing design.

This proves that the fewer the number of discontinuities in designs, the better the design. The results obtained from the 


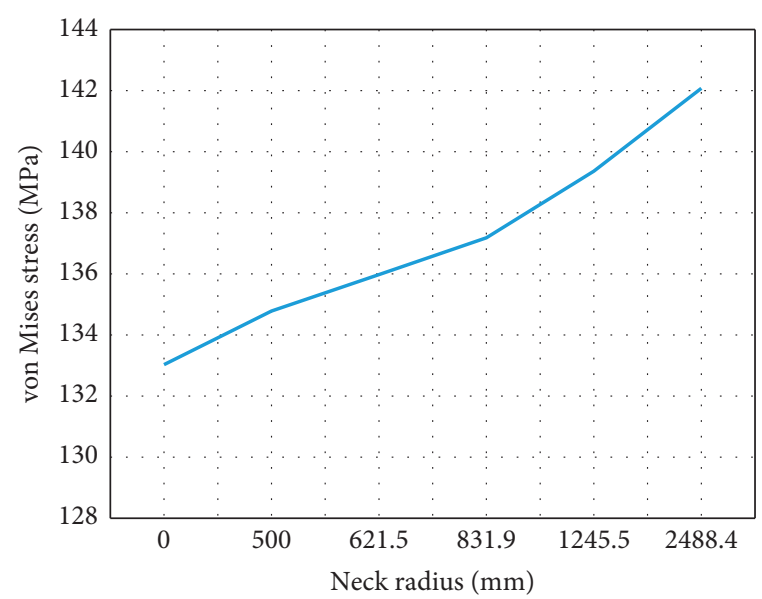

(a)

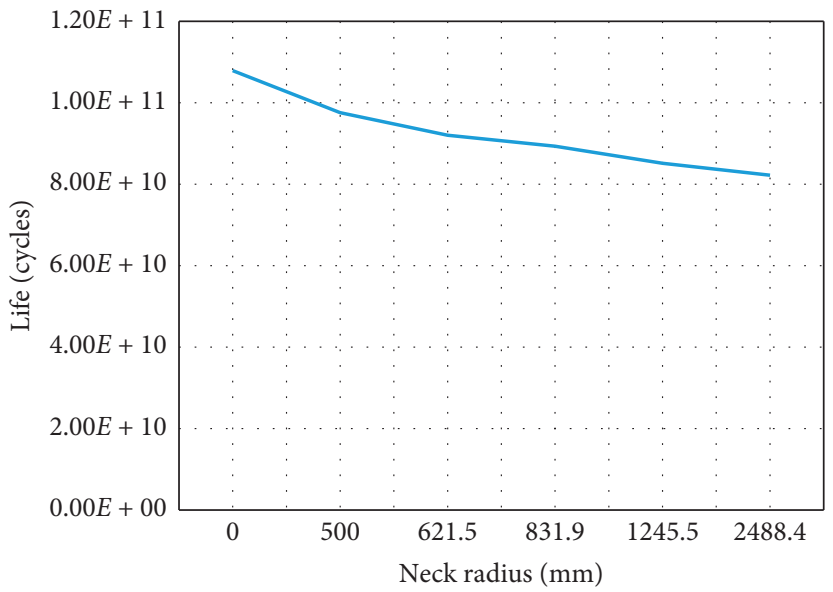

(c)

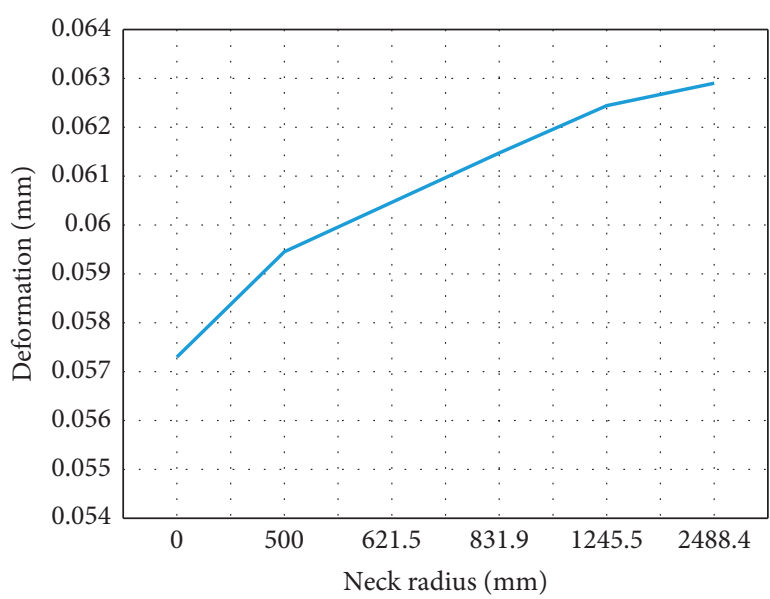

(b)

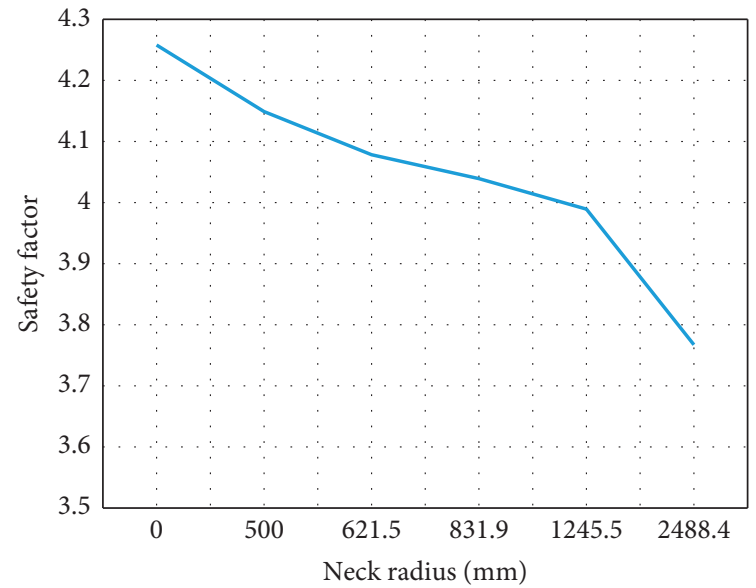

(d)

Figure 20: A graph of results for designs with different neck radii and with modeled crack: (a) equivalent stress verses neck radius, (b) deformation versus neck radius, (c) fatigue life versus neck radius, and (d) safety factor versus neck radius.

simulation tend to support the experimental results in that the life of the existing chain link reduced when the inclusion which was modeled as a crack was introduced. From the experimental results, the cause of failure was found to be from inclusions as already shown in Figures 13 and 20. Juvonen [18] in his study on effects of nonmetallic inclusions on fatigue properties of calcium-treated steels concluded that the fatigue properties of steels are decreased by inclusions. From the simulation results, the life of the chain link reduced when modeled with the inclusion existing within the chain link which was in agreement with the findings made by Juvonen.

\section{Conclusion}

From this research, it has been established that necking and inclusions tend to increase von Mises stress and deformation whilst reducing the fatigue life and safety factor of conveyor chain links. This has negative effect on the performance of the chain link as it increases the likelihood of failure occurring during operation. The combined effect of inclusions and necking resulted in an $18.32 \%$ decrement in the fatigue life of the chain link. It is, therefore, recommended that necking be eliminated from the design and also stress concentration factors for inclusions should be considered in the design of the chain links.

\section{Data Availability}

These data were obtained using ANSYS student.

\section{Conflicts of Interest}

The authors declare that they have no conflicts of interest.

\section{Acknowledgments}

The authors thank the University of Mines and Technology (UMaT), the Mobility to Enhance Training of Engineering Graduates in Africa (METEGA), and REFUROM for funding our research. Our gratitude also goes to East African Portland Cement for availing their plant to us and providing us with the bucket elevator conveyor chain links. 


\section{References}

[1] I. A. Daniyan, A. O. Adeodu, and O. M. Dada, "Design of a material handling equipment: belt conveyor system for crushed limestone using 3 roll idlers," Journal of Advancement in Engineering and Technology, vol. 1, no. 1, pp. 1-7, 2014.

[2] M. D. Jagtap, B. D. Gaikwad, and P. M. Pawar, "Study of roller conveyor chain strip under tensile loading," International Journal of Modern Engineering Research (IJMER), vol. 4, no. 5, pp. 61-66, 2014.

[3] E. Yin, O. Muvengei, J. Kihiu, and K. Njoroge, "Failure analysis on conveyor chain links of a central bucket elevator," IOSR Journal of Mechanical and Civil Engineering, vol. 13, no. 4, pp. 56-63, 2016.

[4] V. Singh, "Inclusion Modification in Steel Castings using Automated Inclusion Analysis," Ph.D. thesis, Missouri Universityof Science and Technology, Rolla, MO, USA, 2009.

[5] F. Tehovnik, J. Burja, B. Arh, and M. Knap, "Submerged entry nozzle clogging during continuous casting of aluminiumkilled steels," Metalurgija, vol. 2, no. 54, pp. 371-374, 2015.

[6] E. Y. Martinez, K. D. Peaslee, and S. N. Lekakh, "Calcium Wire Ladle Treatment to Improve Cleanliness of Centrifugally Cast Steel," pp. 1-7, American Foundary Association, Schaumburg, IL, USA, 2011.

[7] M. Lind, "Mechanism and kinetics of transformation of aluminium inclusions in steel by calcium treatment," Ph.D.thesis, Helsinki University of Technology, Espoo, Finland, 2006.

[8] H. K. Kulkarni and R. J. Patil, "Failure analysis and weight optimization of chain conveyor system," International Journal of Advanced Engineering Research and Studies, vol. 4, no. 2, pp. 23-26, 2015.

[9] B. P. Ravindra, V. H. Waghmare, and S. D. Chavan, "Roller chain link plate design based on FEA," International Journal on Recent and Innovation Trends in Computing and Communication, vol. 2, no. 12, pp. 4109-4113, 2014.

[10] P. R. Barge and M. U. Gaikwad, "Design optimization of roller chain link plate used in sugar industry," International Research Journal of Engineering and Technology (IRJET), vol. 4, no. 2, pp. 482-487, 2016.

[11] A. B. Sutar and G. E. Kondhalkar, "Optimization of weight of roller chain inner link plate for typical industrial chain application," International Journal of Innovations in Engineering Research and Technology IJIERT, vol. 3, no. 3, pp. 4109-4113, 2016.

[12] S. Noguchi, K. Nagasaki, S. Nakayama, T. Kanada, T. Nishino, and T. Ohtani, "Static stress analysis of link plate of roller chain using finite element method and some design proposals for weight saving," Journal of Advanced Mechanical Design, Systems, and Manufacturing, vol. 3, no. 2, pp. 159-170, 2009.

[13] S. Bhosale and A. R. Patil, "Weight optimization of chain link using glass fiber composite as alternative material," International Journal for Scientific Research \& Development, vol. 6, no. 10, pp. 654-661, 2018.

[14] M. S. Kamble, V. D. Yelpale, and R. N. Panchal, "Weight optimization using topological approach and strength evaluation of chain link plate," International Journal of Innovative Research in Science, Engineering and Technology, vol. 5, no. 7, 2016.

[15] T. S. Shahane and A. M. Umbrajkaar, "Design and analysis of chain outer link by using composite material," IOSR Journal of Mechanical and Civil Engineering (IOSR-JMCE), vol. 12, no. 1, pp. 46-50, 2016.
[16] Beumer, "Conveying Technology Loading Technology Palletizing Technology Packaging Technology Sortation and Distribution Systems," Beumer, Beckum, Germany, 2015.

[17] R. Budynass and K. Nisbett, Shigleys Mechanical Engineering Design, MacGraw-Hill, New York, NY, USA, Ninth edition, 2011.

[18] P. Juvonen, "Effects of non-metallic inclusions on fatigue properties of calcium treated steels," Ph.D. thesis, Helsinki University of Technology, Espoo, Finland, 2004. 